\title{
Evolution of Mesoscale Convective System Organizational Structure and Convective Line Propagation $\mathscr{O}$
}

\author{
DAVID J. BODINE \\ Advanced Study Program, National Center for Atmospheric Research, ${ }^{\mathrm{a}}$ Boulder, Colorado, and \\ Advanced Radar Research Center, University of Oklahoma, Norman, Oklahoma \\ KRISTEN L. RASMUSSEN \\ Advanced Study Program, National Center for Atmospheric Research, ${ }^{\text {a }}$ Boulder, and Department of \\ Atmospheric Science, Colorado State University, Fort Collins, Colorado
}

(Manuscript received 21 October 2016, in final form 24 April 2017)

\begin{abstract}
This study examines organizational changes and periods of rapid forward propagation in an MCS on 6 July 2015 in South Dakota. The MCS case was the focus of a Plains Elevated Convection at Night (PECAN) IOP. Data from the Sioux Falls WSR-88D and a high-resolution WRF simulation are analyzed to examine two periods of rapid forward propagation (or surges) and organizational changes. During the first surge (surge A), the northern portion of the convective line propagates eastward faster than the southern portion, and the northern portion of the leading line transitions from a single convective core to a multicellular structure as it merges with convection initiation. Radar reflectivity factor $Z$ and graupel concentrations decrease above the melting layer, while at lower altitudes $Z$ increases. The MCS cold pool also intensifies and deepens beneath an expanded region of high rainwater content and subsaturated air. Throughout surge A, a mesoscale circulation with strong rear-to-front near-surface flow and front-to-rear midlevel flow is also evident. By the end of surge A, the leading edge of the MCS cold pool is beneath developing convection initiation ahead of the original convective line while the original convective updraft weakened and moved rearward. This MCS evolution is similar to discrete propagation events discussed in past studies, except with new convection developing along an intersecting convective band. During surge B, the MCS transitions from a multicellular structure to a single, intense updraft. Smaller microphysical and thermodynamic changes are observed within the MCS during surge B compared to surge A, and the mesoscale circulation continues to develop.
\end{abstract}

\section{Introduction}

Mesoscale convective systems (MCSs; Houze 2004) are a substantial contributor to precipitation and severe weather hazards in the United States and globally. In the Great Plains region, MCSs contribute $30 \%-70 \%$ of warm season precipitation with the highest contribution during the summer months (Fritsch et al. 1986). In other regions

\footnotetext{
${ }^{a}$ The National Center for Atmospheric Research is sponsored by the National Science Foundation.
}

Supplemental information related to this paper is available at the Journals Online website: http://dx.doi.org/10.1175/ MWR-D-16-0406.s1.

Corresponding author: David Bodine, bodine@ou.edu (e.g., South America), MCSs are also very large contributors to warm season precipitation (Rasmussen et al. 2016). In addition to contributing to the total rainfall budget, MCSs also produce extreme rainfall events. Schumacher and Johnson (2005) found that MCSs caused $65 \%$ of extreme rainfall events east of the Rocky Mountains, and these events often occurred with MCSs characterized by training or back building convection. MCSs are responsible for a large proportion of severe wind events (e.g., Johns 1993; Smith et al. 2013), and approximately $20 \%$ of tornado reports (Trapp et al. 2005).

The severe weather hazards and rainfall potential of MCSs are related to specific organizational structure or characteristics of MCSs. Houze et al. (1990) noted that severe weather reports and heavy rainfall were most common in MCSs with convex, leading lines and large regions of stratiform rain. Bow echoes are commonly associated with severe winds and tornadoes (Weisman 
1993; Trapp et al. 2005). Based on radar observations, several classifications of MCSs have been developed. Bluestein and Jain (1985) divided developing MCSs into broken line, back building, embedded areal, and broken area. For developed MCSs, the most common archetype is the leading-line, trailing-stratiform MCS (e.g., Zipser 1977; Smull and Houze 1985, 1987; Rutledge et al. 1988; Houze et al. 1990; Biggerstaff and Houze 1991). Houze et al. (1990) separated the leading-line, trailing-stratiform archetype into symmetric and asymmetric, and found differences in severe weather potential depending on the symmetry and degree of organization of the MCS. Another classification for MCSs is based on the orientation of stratiform rain relative to the convective line's movement (Parker and Johnson 2000). In their study, the most common MCS archetype is the leading-line, trailingstratiform (TS) archetype that comprises approximately $60 \%$ of MCSs, while parallel and leading stratiform occur in the remaining $40 \%$. They observed different upperlevel, environmental wind profiles associated with different archetypes, and transitions between different archetypes at different life cycle stages.

Several factors affect MCS propagation including the environmental flow, internal storm processes related to cold pool development, and nearby convection and its interaction with the MCS. Corfidi et al. (1996) found that mesoscale convective complex motion was related to both the mean wind and propagation associated with new convection. The propagation component is similar in magnitude to the low-level jet vector, but in the opposite direction. These motion estimates were further refined in Corfidi (2003) to incorporate the effects of the cold pool. In some cases, the MCS may propagate in the direction of new convection initiation and merge with the new convection, leading to enhanced forward propagation through discrete propagation (e.g., Zipser 1977; Crook and Moncrieff 1988; Fovell et al. 2006). Fovell et al. (2006) explored discrete propagation using a numerical model and found that new convection was initiated by gravity waves ahead of the leading line. If the new convection becomes sufficiently deep prior to the merger, it develops a cold pool and leads to a discrete "jump" in the position of the MCS cold pool and leading line.

MCS cold pools develop beneath downdrafts with substantial diabatic cooling caused by evaporation and melting. Since cold pool characteristics impact MCS structure and dynamics (e.g., Rotunno et al. 1988; Fovell and Ogura 1989), MCS structure and dynamics are inherently coupled to thermodynamic and microphysical processes affecting the cold pool. Leary and Houze (1979) found that evaporation was the primary contributor to cooling rates in the cold pool, producing cooling of up to $6 \mathrm{~K} \mathrm{~h}^{-1}$. Subsequent studies have also identified that evaporative cooling is important in the stratiform region (Szeto et al. 1988a, b). Within the convective line, melting contributes substantially to cold pools. Braun and Houze (1995) found that cooling rates in the convective region were as large as $14 \mathrm{~K} \mathrm{~h}^{-1}$ and melting contributed more than half of the total cooling in the mature phase. Tao et al. (1995) also found that excluding melting from their simulations led to a single cellular convective structure rather than a multicellular structure, and thus melting impacted convective organization.

Nocturnal low-level cooling impacts MCS evolution, and can lead to elevated MCSs. Parker (2008) conducted idealized squall-line simulations to explore the effects of nocturnal cooling on MCS evolution. They found that nocturnal cooling tends to weaken updraft intensity, although some MCSs intensified because the ratio of cold pool intensity and low-level shear became more favorable (Rotunno et al. 1988). Moreover, they note that MCSs can remain surface-based even with substantial low-level cooling since the cold pool was sufficiently intense to lift parcels to the level of free convection. In addition to these findings, they identified four stages of nocturnal MCSs: strengthening, quasisteady, stalling, and elevated. In the strengthening stage, the MCS becomes better organized, the surface cold pool becomes more intense, and MCS speed increases. In the quasi-steady stage, MCS motion is approximately constant and the MCS remains intense.

Although studies have focused on general propagation characteristics of MCSs (e.g., fast vs slow moving MCSs), few studies have specifically addressed the transition stage between MCS propagation speeds. Thus, the objective of this study is to assess possible causes of these propagation changes by examining internal and external factors to MCS evolution, and to explore thermodynamic, microphysical, and kinematic changes within the MCS. Internal factors such as an intensifying cold pool or rear-inflow jet could lead to a faster propagating MCS. External factors, such as discrete propagation events, could also cause faster MCS propagation.

The present study examines a nocturnal MCS on 6 July 2015 in South Dakota that occurred during the Plains Elevated Convection at Night (PECAN; Geerts et al. 2017) field experiment and was the focus of PECAN intensive observing period (IOP) 20. This MCS underwent two distinct periods during which the MCS underwent a transition from slow to fast forward propagation, thus providing an opportunity to evaluate potential causes of these propagation transitions and MCS structural changes occurring during and after these transitions. To investigate MCS changes during these transitions, including thermodynamic, microphysical, and kinematic changes, analyses are conducted using 
WSR-88D data and the Advanced Research core of the Weather Research and Forecasting (WRF) Model (ARW; Skamarock and Klemp 2008) simulation. The WRF simulation allows an examination of MCS processes for a real case that have been studied primarily using idealized simulations, and similarities and differences between idealized simulations and the WRF simulation will be discussed. In the analyses, comparisons of dual-polarization WSR-88D data and WRF variables are also conducted to illustrate the capability of using dual-polarization radar data to evaluate hydrometeor characteristics in real case WRF simulations.

This study is organized in the following manner. In section 2, radar data and analysis methods are described, and the WRF simulation configuration is discussed. In section 3, a synoptic-scale overview of the MCS case is presented and the general evolution of the MCS prior to the specific study period is described. The analysis of the radar and WRF data are presented in section 4, and the conclusions are summarized and discussed in section 5 .

\section{Data and methods}

\section{a. WSR-88D data and processing}

Dual-polarization level-II radar data from the Sioux Falls, South Dakota (KFSD), WSR-88D are used to examine structural changes in the MCS. During the period of study (0400-0600 UTC), KFSD operated in volume coverage pattern (VCP) 12 providing an update time of about $4 \mathrm{~min}, 50 \mathrm{~s}$. To ensure high data quality, several data processing steps were applied to remove nonmeteorological scatterers, correct attenuation, and check differential reflectivity $Z_{\mathrm{DR}}$ calibration. The NCAR particle identification algorithm (PID; Vivekanandan et al.1999) was applied to the KFSD data to identify and remove nonmeteorological scatterers. Radar reflectivity factor $Z$ and $Z_{\mathrm{DR}}$ are also corrected for attenuation and differential attenuation using a linear relation with specific differential phase $K_{\mathrm{dp}}$ with coefficients $^{1}$ of $\alpha=0.04$ to correct $Z$ and $\beta=0.0088$ to correct $Z_{\mathrm{DR}}$. WSR-88D $Z_{\mathrm{DR}}$ calibration was also checked by examining the mean $Z_{\mathrm{DR}}$ throughout the period of study in dry snow regions identified by the PID algorithm. The mean value of $0.20 \mathrm{~dB}$ compares well with the expected value for dry snow aggregates of less than $0.25 \mathrm{~dB}$ (Ryzhkov et al. 2005).

After data processing steps are completed, the processed radar data are interpolated onto a three-dimensional grid

\footnotetext{
${ }^{1}$ These coefficients are based on MCS cases from Ryzhkov and Zrnić (1994, 1995).
}

through the following process. Radar data are linearly interpolated on their respective elevation planes to a 2-km resolution, similar to Homeyer and Kumjian (2015), and then are linearly interpolated at $1-\mathrm{km}$ intervals in height. Using the three-dimensional gridded data, contoured frequency by altitude diagrams (CFADs) are computed following Yuter and Houze (1995). CFADs provide a frequency distribution of radar data as a function of height, and are a useful tool to explore statistical characteristics of convective systems. In this study, the analyses focus on the region of the MCS that undergoes enhanced forward propagation and changes in MCS organization. To examine changes in radar variables within this region, CFADs are computed within manually identified regions as described and shown in section 3 .

\section{b. WRF simulation: Mesoscale modeling framework}

The WRF Model, version 3.6.1 (Skamarock et al. 2008), is used to conduct a high-resolution simulation of the 6 July 2015 MCS in South Dakota. The WRF Model is a fully compressible, nonhydrostatic, and threedimensional community mesoscale model developed by the National Center for Atmospheric Research with many user-contributed physics parameterizations. The platform supports many options for microphysics, land surface, cumulus and shallow convection, planetary boundary layer, surface layer, and radiation parameterizations. The WRF Model has been used extensively to model weather and climate phenomena, thus these parameterizations have been reasonably well tested. For this study, the following parameterizations were used: Morrison microphysics (Morrison et al. 2005), Noah land surface scheme (Chen and Dudhia 2001), Kain-Fritsch cumulus parameterization (Kain and Fritsch 1993) in the outer domains (convection is explicitly resolved in the inner domain), YSU planetary boundary layer (Hong et al. 2006), the Rapid Radiative Transfer Model (RRTM) longwave radiation scheme (Mlawer et al. 1997), and the Dudhia shortwave radiation scheme (Dudhia 1989). Simulations using Thompson microphysics (Thompson et al. 2004) and the same physics parameterizations above were also conducted. However, the simulations with Thompson microphysics produced less realistic stratiform rain regions and did not capture the discrete propagation events as well as the simulations using Morrison microphysics.

The model was initialized with $0.25^{\circ}$-resolution GFS data at 0000 UTC 5 July 2015 and run for 48 h using a triple-nested domain of 27, 9, and $3 \mathrm{~km}$ (Fig. 1). Each of the domains used two-way nesting and 44 uneven vertical levels with maximum resolution in the boundary layer. In 


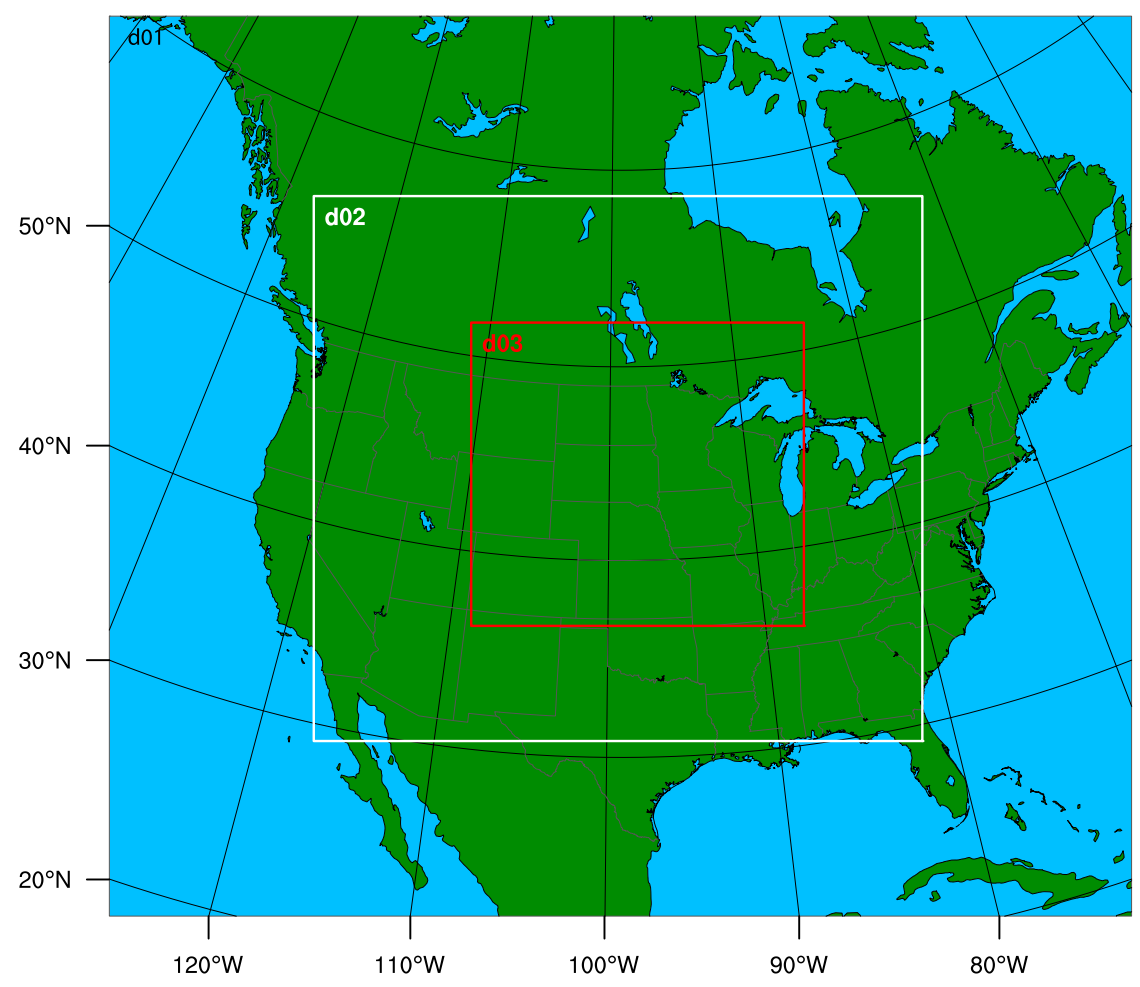

FIG. 1. WRF domains for the three nests at resolutions of $27 \mathrm{~km}$ (d01), $9 \mathrm{~km}$ (d02), and $3 \mathrm{~km}$ (d03). The finest grid is approximately centered on eastern South Dakota where the MCS develops.

the innermost domain (d03; Fig. 1), model output is produced at 5-min intervals to match the temporal resolution of the WSR-88D data described in section 2a.

\section{Synoptic and mesoscale overview}

\section{a. Synoptic overview and MCS development}

An MCS developed in central and eastern South Dakota on 6 July 2015 with synoptic-scale conditions favorable for MCS formation and maintenance. Data from the NCEP-NCAR reanalysis at 0000 UTC 6 July 2015 are presented to highlight characteristics of the synoptic-scale environment. The MCS formed east of a 500-hPa short-wave trough located in eastern Montana and Wyoming (Fig. 2a), providing focused ascent in South Dakota. The 500-hPa winds exhibit a substantial meridional gradient in $500-\mathrm{hPa}$ flow with weaker 500-hPa flow in southern South Dakota compared to northern South Dakota. At $850 \mathrm{hPa}$, a strong low-level jet is evident across the Great Plains region collocated with the strong gradient in the 850-hPa heights (Fig. 2b). The low-level jet terminates along the $850-\mathrm{hPa}$ cold front position, leading to strong convergence along an axis from northeast Colorado to eastern South Dakota.
Precipitable water exceeds $40 \mathrm{~mm}$ in central and eastern South Dakota, indicating substantial availability of moisture and high rainfall potential (Fig. 2c). Over the 24-h period, TRMM 3B42 data show that over $30 \mathrm{~mm}$ of rainfall occurred over much of southeast South Dakota and northeast Nebraska, and thus the MCS produced considerable rainfall over the region (Fig. 2d).

The study focuses on the mature stage of the MCS. For interested readers, an animation of KFSD base elevation $Z$ is provided to show the general evolution of the MCS between 0000 and 0800 UTC (see online supplemental Fig. S1), and includes the developing stage. The MCS originated in south-central South Dakota, and convective initiated along the cold front in northeast South Dakota around 0000 UTC and organized into a convective line that developed southwestward with time between 0000 and 0300 UTC (not shown).

Since the study examines WSR-88D and WRF data from the 6 July 2015 MCS case, comparisons of WSR88D mosaics and 2-km WRF radar reflectivity factor are shown in Fig. 3 for a larger domain and longer time steps $(1.5 \mathrm{~h})$ than the forthcoming focused analyses. The WSR88D mosaics were obtained from the PECAN field catalog (UCAR/NCAR Earth Observing Laboratory 2016), and the mosaics are valid at approximately the same time 

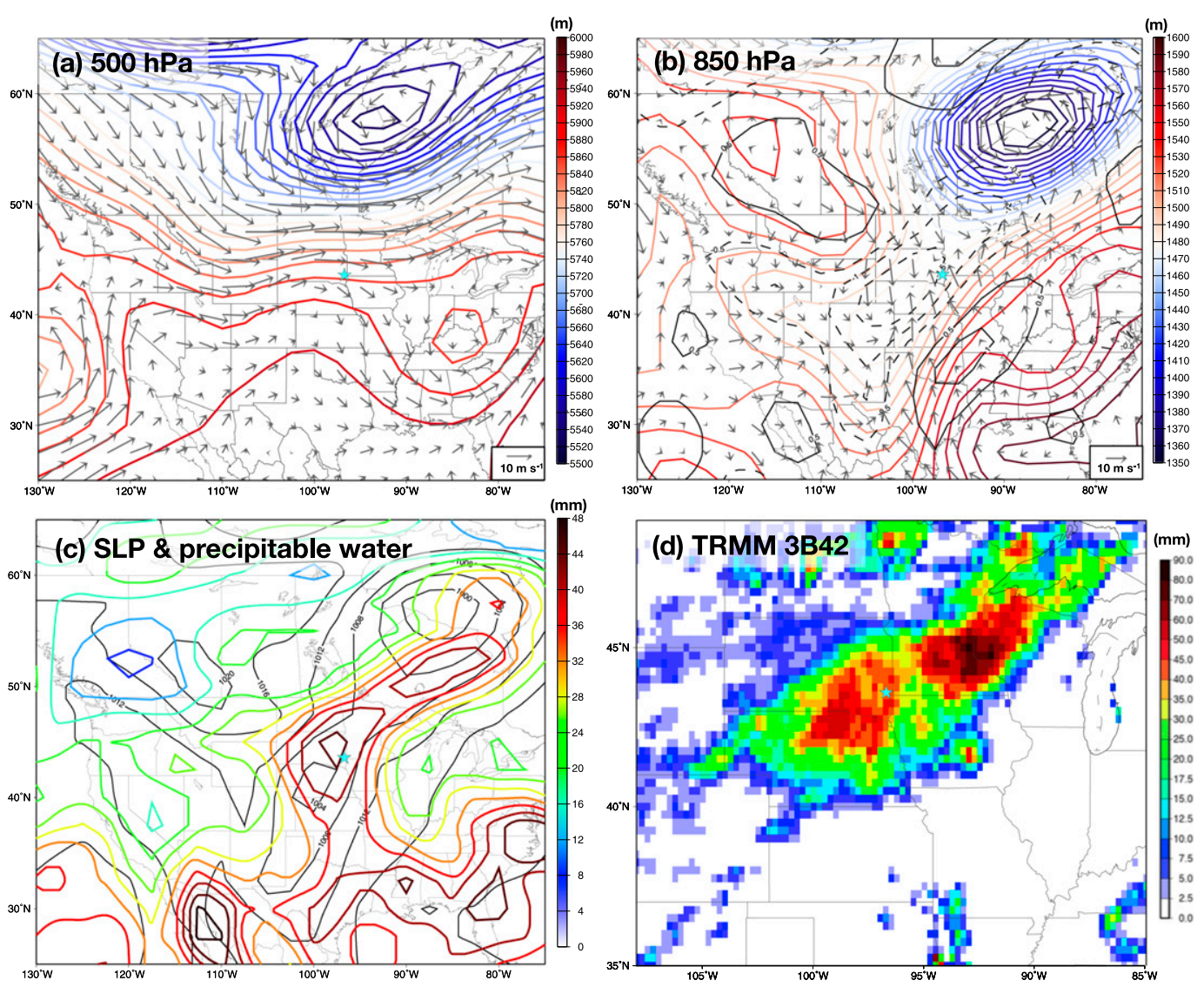

FIG. 2. Overview of synoptic weather conditions including (a) NCEP-NCAR reanalysis 500-hPa heights (m; shaded contours) and wind vectors; (b) NCEP-NCAR reanalysis $850-\mathrm{hPa}$ height ( $\mathrm{m}$; shaded contours), wind vectors, and divergence (convergence) in solid (dashed) black contours; (c) NCEP-NCAR reanalysis mean sea level pressure (hPa; solid black contours) and precipitable water (shaded contours); and (d) TRMM 3B42 total precipitation $(\mathrm{mm})$ from 1200 UTC 5 Jul to 1200 UTC 6 Jul 2015. NCEP-NCAR reanalysis data are plotted at 0000 UTC 6 Jul 2015, and the location of the KFSD WSR-88D is shown by the blue star.

as the WRF output (2 min earlier). At 0300 UTC, the WSR-88D mosaic and WRF data show a similar largescale reflectivity pattern (Figs. 3a,b). Both images depict a mature leading-line, trailing-stratiform MCS, and a convective band extending from northeast South Dakota through Minnesota. A gap is evident between the convective band and MCS in both the WSR-88D mosaic and WRF Model. Finally, the WRF Model captures extensive stratiform rain behind the convective line and MCS, and areas of convection in Nebraska. By 0430 UTC, in both the WSR-88D and WRF data the convective band has continued to develop southwest and intersects the MCS (Figs. 3c,d). The extent of trailing stratiform rain continues to increase by 0600 UTC (Figs. 3e,f), and a mature MCS is still evident in eastern South Dakota in both WSR-88D and WRF data.

Some notable differences are observed between the WSR-88D mosaic and WRF output. First, the MCS and convective band in the WRF simulation are displaced to the northwest compared to its true position. The WRF simulation also produces an MCS convective line with a northwest-southeast orientation at the earlier times whereas the MCS convective line has a north-south orientation in the WSR-88D data. Even though there are differences in the location and orientation of the MCS, similar MCS and intersecting convective band structure are evident in the reflectivity comparison.

\section{b. Thermodynamic and mesoscale evolution}

Prior to discussing the detailed evolution of the MCS, the thermodynamic characteristics are discussed for two upper-air soundings launched by the Mobile GPS Advanced Upper-Air Sounding (MGAUS) radiosonde teams (Ziegler et al. 2016). The first sounding was launched by the North Carolina State University (NCSU) MGAUS sounding team at 0305 UTC (Fig. 4a) at a distance of about $100-150 \mathrm{~km}$ from the convective band and MCS convective line (Fig. 4b; sounding 

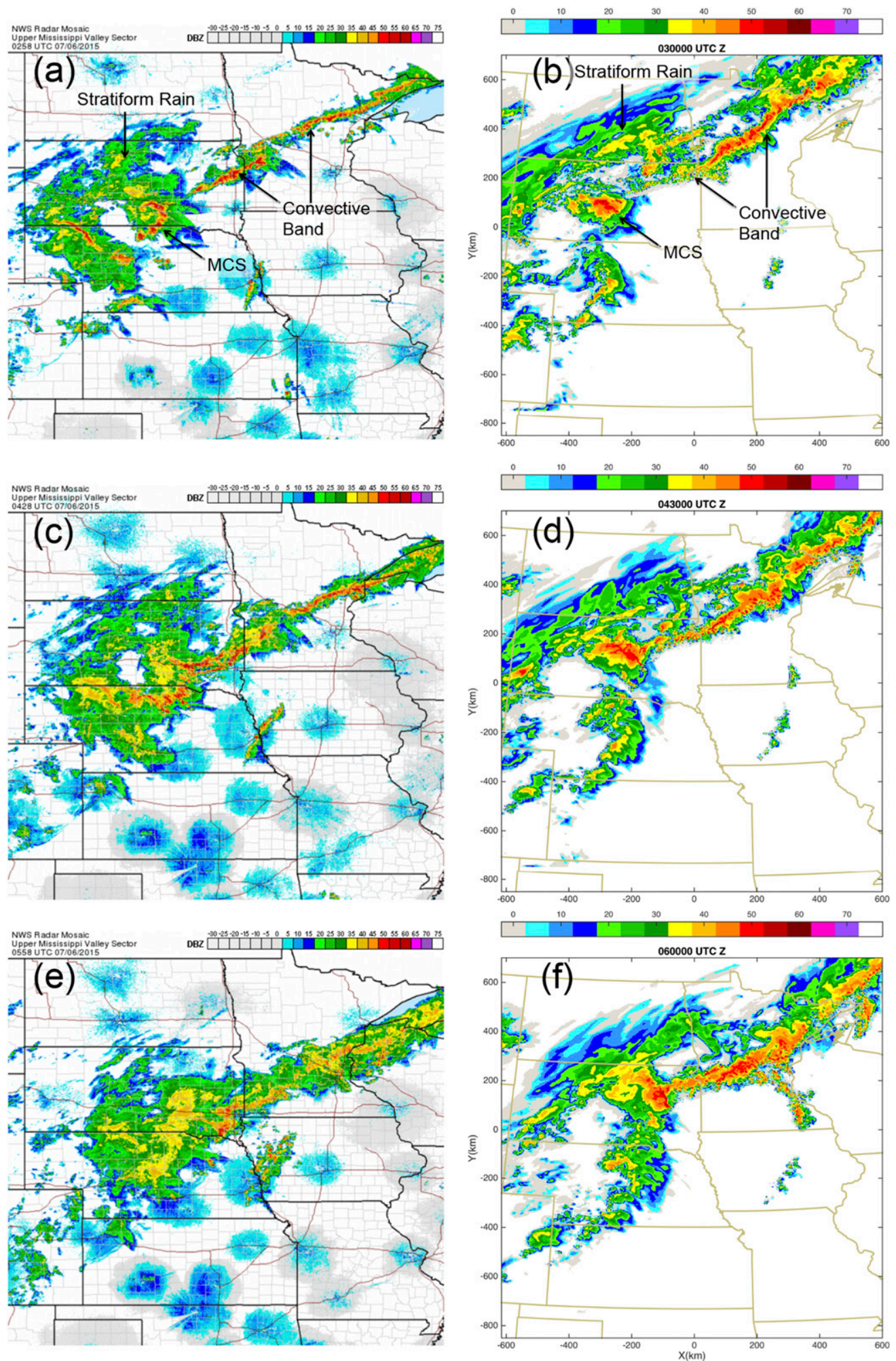

FIG. 3. Radar reflectivity factor mosaics of NEXRAD data are shown at (a) 0258, (c) 0428, and (e) 0558 UTC. The 2-km AGL WRF radar reflectivity factor is shown at (b) 0300, (d) 0430, and (f) 0600 UTC. 

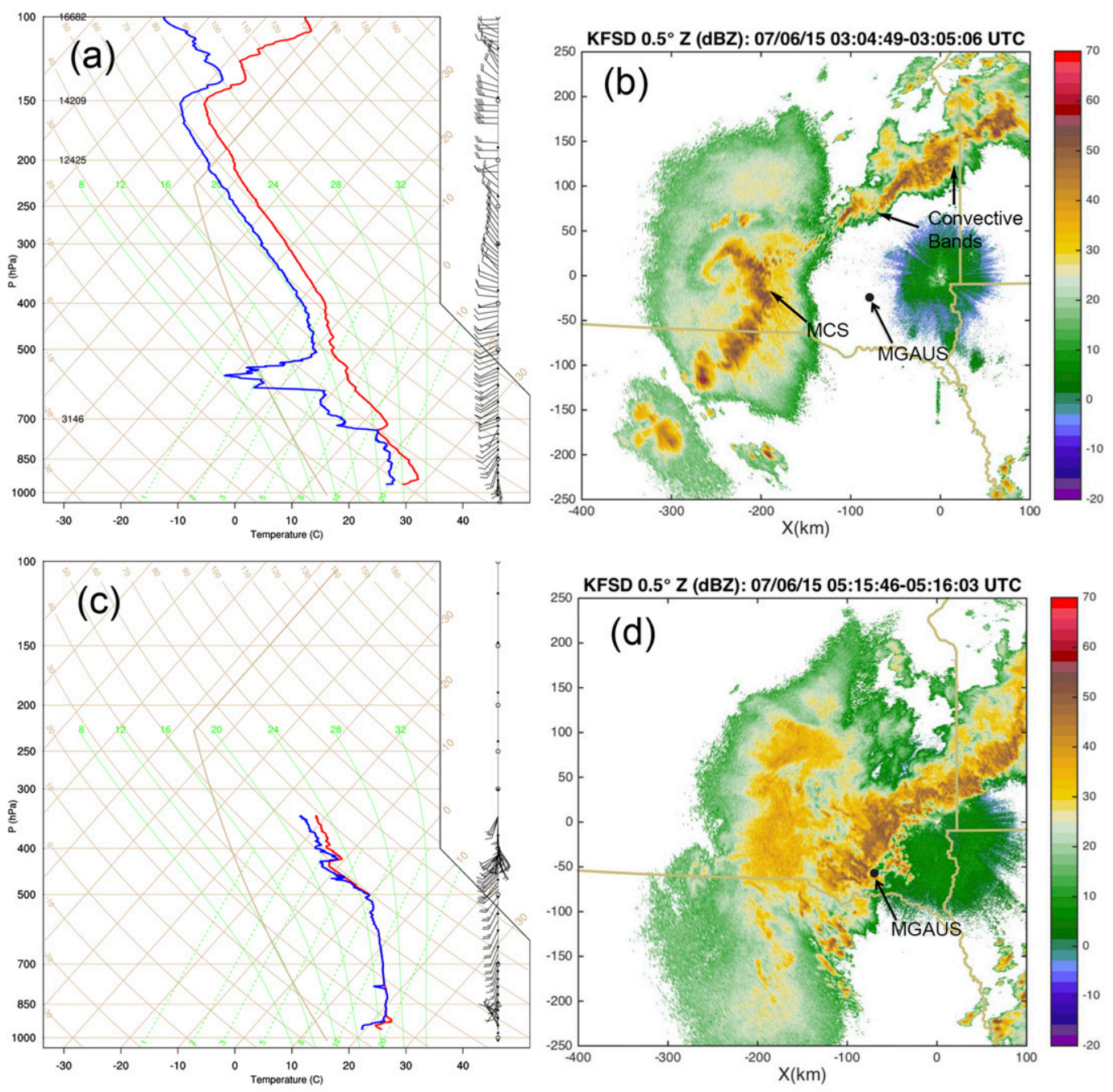

FIG. 4. Skew $T-\log p$ profiles are shown at (a) 0305 and (c) 0516 UTC, and (b),(d) the radar reflectivity factor image at the closest available time is shown for $0.5^{\circ}$ elevation from the Sioux Falls WSR-88D. The red and blue lines are the temperature and dewpoint temperature, respectively. The black circle shows the location where the sounding was launched. At 0305 UTC, the sounding was launched ahead of the MCS convective line. At 0516 UTC, the sounding was launched near the leading edge of the MCS convective line and substantial low-level cooling is evident likely associated with the MCS cold pool.

location is denoted by the asterisk). Computed surfacebased convective available potential energy (CAPE) exceeds $4000 \mathrm{~J} \mathrm{~kg}^{-1}$ and convective inhibition is small (about $50 \mathrm{~J} \mathrm{~kg}^{-1}$ ). Thus, environmental conditions were favorable to sustain intense, deep convection, and convection could remain primarily surface-based. The 0-1and $0-6-\mathrm{km}$ shear values were 26.7 and $14.8 \mathrm{kt}$ (13.7 and $7.6 \mathrm{~m} \mathrm{~s}^{-1}$ ), respectively, indicating strong low-level shear but weaker deep layer shear. Very weak $500-\mathrm{hPa}$ flow is evident in the 0305 UTC, which is consistent with weak flow to the south in the RUC analysis. The 0516 UTC sounding was launched by the Colorado State University MGAUS team (Fig. 4c) near the leading edge of the MCS convective line (Fig. 4d). Instability is still evident above $500 \mathrm{hPa}$ with a saturated layer beneath it. Near the surface, temperatures had cooled by about $5 \mathrm{~K}$ and the wind profile backs with height. Thus, this sounding likely captured at least a portion of the MCS cold pool. Nocturnal cooling also may have contributed to the observed temperature change.

The evolution of the MCS during the study period (0400-0600 UTC) is discussed and comparisons of WSR88D and WRF $Z$ are presented to examine mesoscale characteristics of the MCS. Lowest elevation $\left(0.5^{\circ}\right) Z$ from KFSD is presented in Figs. 5a-c at times that closely correspond to WRF $Z$ at $2 \mathrm{~km}$ AGL (Figs. 5d-f). At 0411 UTC, the leading line of the MCS extends from north to south between $X=-180$ and $-150 \mathrm{~km}$ in KFSD $Z$ (Fig. 5a). 

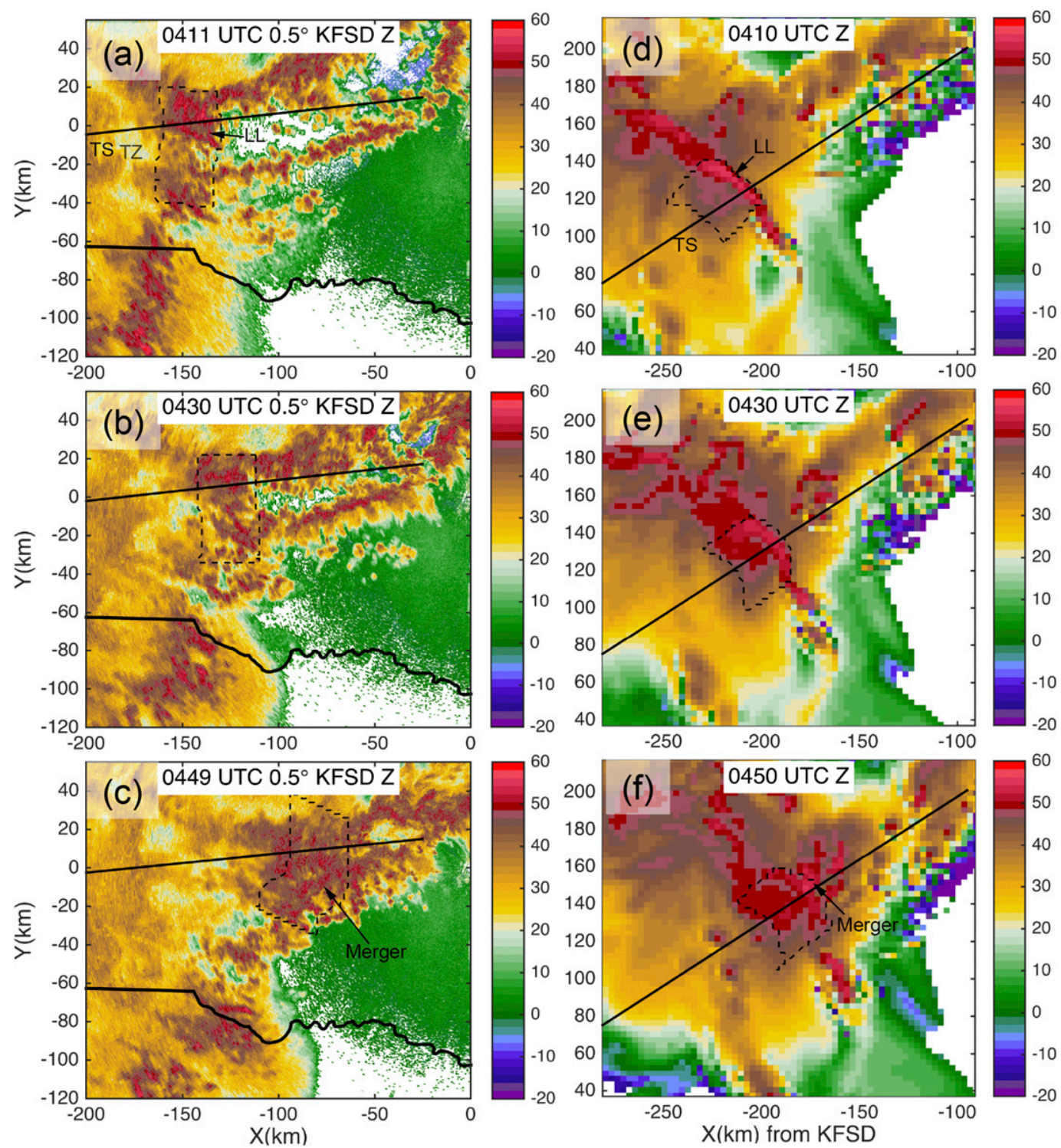

FIG. 5. Radar reflectivity factor from the KFSD WSR-88D at a $0.5^{\circ}$ elevation angle shown at (a) 0411, (b) 0430 , and (c) 0449 UTC and WRF radar reflectivity factor at $2 \mathrm{~km}$ AGL at (d) 0410, (e) 0430, and (f) 0450 UTC. The $x$ and $y$ axes are zonal and meridional distances, respectively, from KFSD. The area enclosed by the black dashed line shows the region used in CFAD analyses of the surge regions, and vertical cross sections are computed along the solid black lines using data within $\pm 22.5 \mathrm{~km}$ of the black line. The leading-line (LL), transition zone (TZ), and trailing-stratiform (TS) regions are also labeled as abbreviated here. The MCS leading line merges with the frontal convective bands at 0450 UTC as noted by the black arrow in (c) and (f).

A trailing stratiform region is also observed with a transition zone (e.g., Smull and Houze 1987; Biggerstaff and Houze 1991) or reflectivity minimum behind the convective line. Although the MCS exhibits some characteristics of a mature MCS, the mesoscale environment is complicated by nearby convection. Two parallel convective bands oriented approximately west-southwest to east-northeast intersect the northern region of the leading line.
Comparing KFSD $Z$ at 0411 UTC (Fig. 5a) to WRF $Z$ at 0410 UTC (Fig. 5d), both depict an MCS with a leading convective line and trailing stratiform region and frontal convective bands intersect the northern portion of the MCS leading line. As noted previously, two differences include displacement of the MCS and convective line orientation. The convective line in KFSD has a north-south orientation (Fig. 5a) whereas the convective line in the WRF simulation has a 

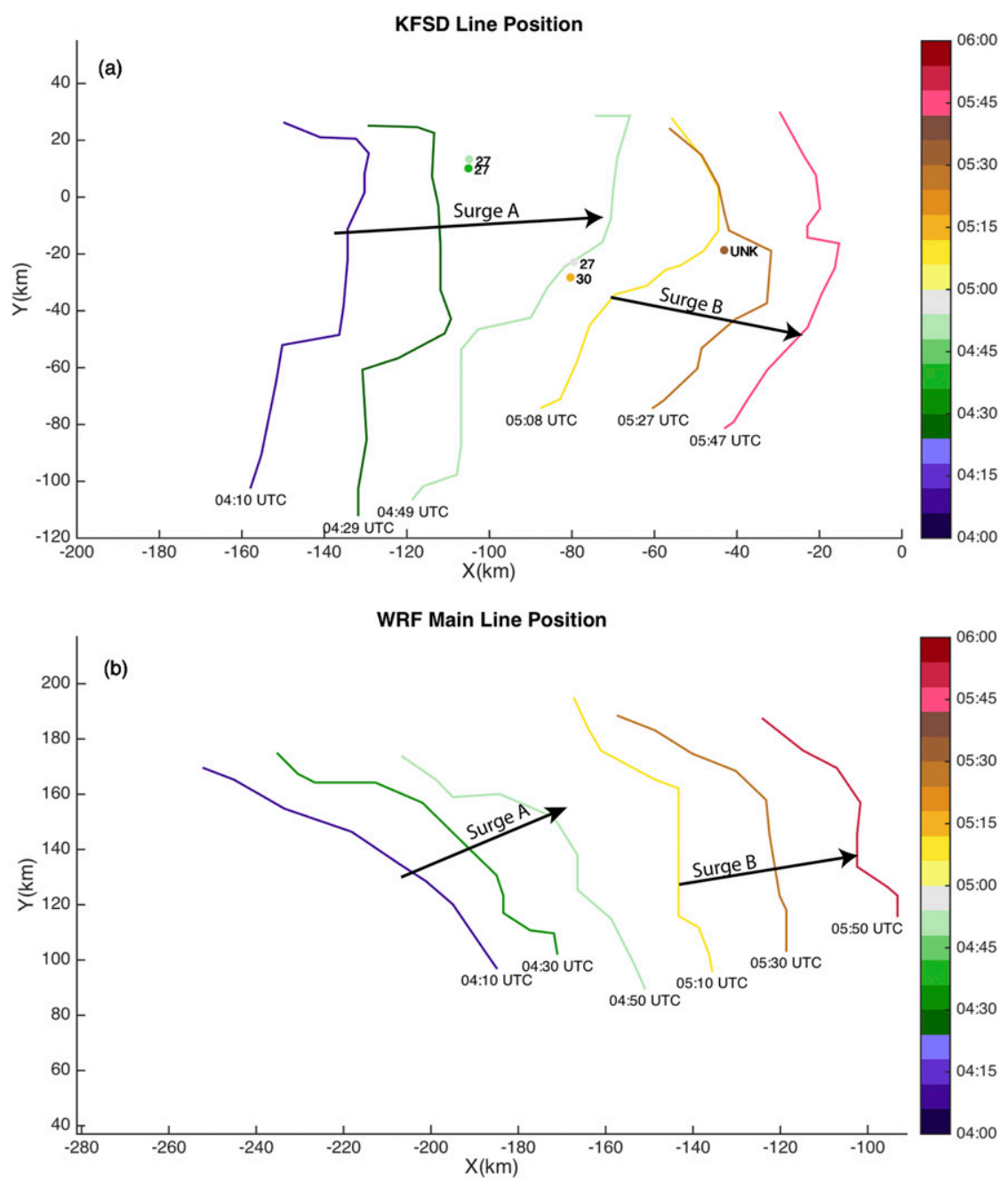

FIG. 6. Isochrones of (a) KFSD and (b) WRF $Z$ between 0410 and 0550 UTC. Severe wind reports are also shown in (a) with the colors representing time, and the text labels showing the velocity $\left(\mathrm{m} \mathrm{s}^{-1}\right)$ except when unknown (UNK). The locations of surges A and B are also annotated with the black arrows in both panels.

northwest-southeast orientation (Fig. 5d). In Figs. 5d-f, it should be noted that the $x$ and $y$ axes have different values compared to Figs. $5 \mathrm{a}-\mathrm{c}$ as a result of the spatial displacement of the MCS in the WRF simulation (approximately $81 \mathrm{~km}$ to the west and $157 \mathrm{~km}$ to the north compared to KFSD).

Between 0410 and 0450 UTC, the northern portion of the MCS convective line evolves substantially in both the KFSD and WRF $Z$, and the WRF Model captures structural changes associated with a merger with the intersecting convective band with very similar timing to observations. In KFSD $Z$, the northern portion of the convective line moves eastward faster than the southern portion of the convective line, and propagates into the intersecting convective band region (Figs. 5a-c). The convective line propagation characteristics can also be seen at higher temporal resolution in the supplemental animation (see Fig. S1). During this period, the distance separating the intersecting convective bands also decreases. By 0449 UTC, the northern portion of the MCS leading-line position becomes more poorly defined as it merges with the intersecting convective bands (Fig. 5c). In WRF $Z$, a similar process is observed with the northern portion of the convective line merging with an intersecting convective band (cf. multiple bands observed by KFSD) and surging eastward relative to the southern portion of the convective line (Figs. 5d-f).

To visualize these changes in MCS leading-line position, isochrones of $Z$ are computed based on the subjectively determined position of the leading line, and are shown in Fig. 6. An objective method of a specific $Z$ threshold was not chosen since convection intersects the 

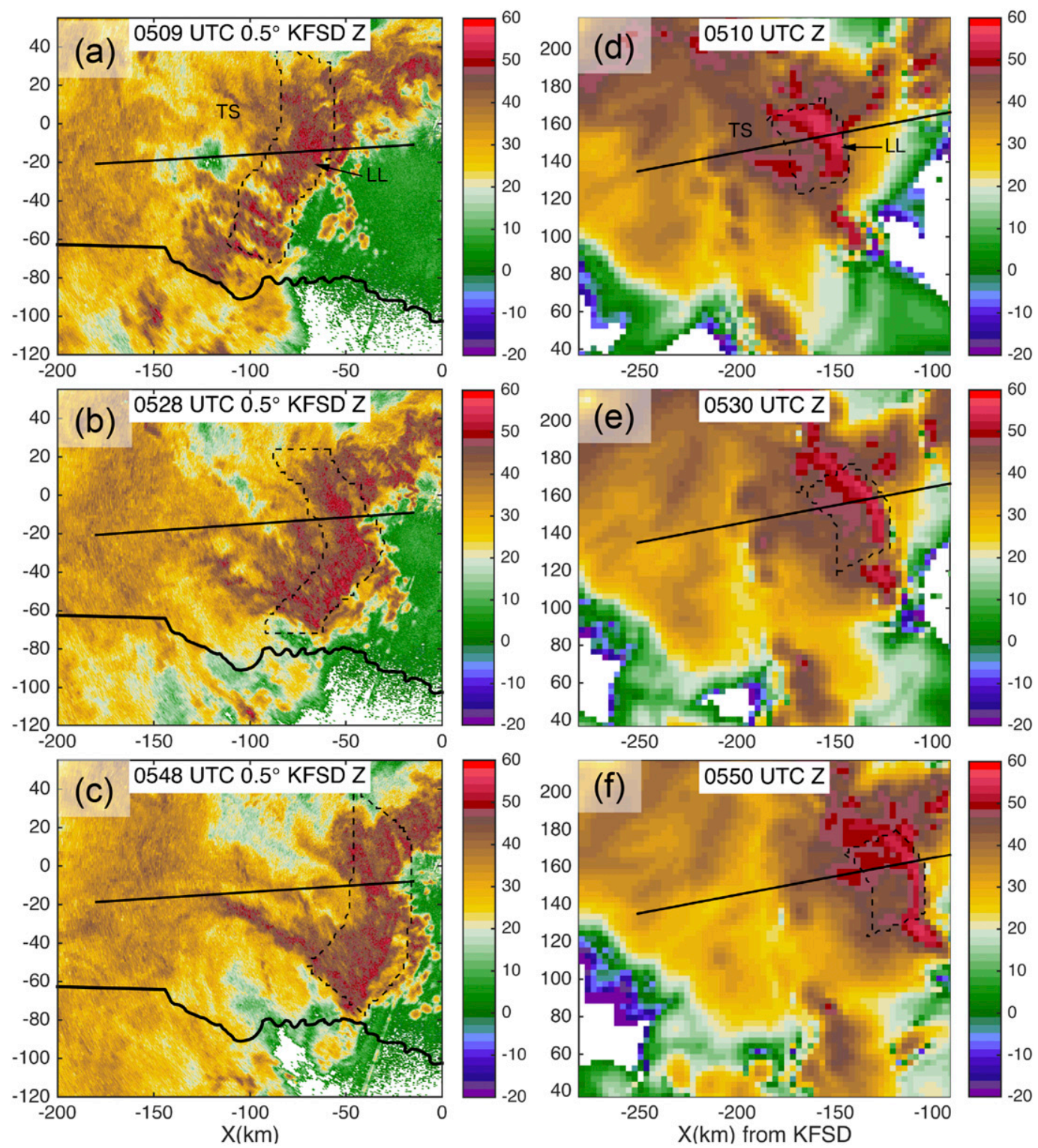

FIG. 7. As in Fig. 5, but for radar reflectivity factor from the KFSD WSR-88D at a $0.5^{\circ}$ elevation angle shown at (a) 0509, (b) 0528, and (c) 0548 UTC and WRF radar reflectivity factor at $2 \mathrm{~km} \mathrm{AGL} \mathrm{at} \mathrm{(d)} \mathrm{0510,} \mathrm{(e)} \mathrm{0530,} \mathrm{and}$ (f) 0550 UTC.

primary convective line, and makes the determination of the leading-line position more challenging from a single $Z$ threshold. The isochrone plots show the northern portion of the convective line moving eastward faster than the southern portion between 0410 and 0450 UTC. In subsequent analyses, the period from 0410 to 0450 UTC is called surge $\mathrm{A}$, and the forthcoming discussion focuses on surge B (0510-0550 UTC).

Surge B occurs during a period of MCS reorganization and a second period of enhanced forward propagation within the southern portion of the leading line. At 0509 UTC in KFSD $Z$, the MCS leading line exhibits a more continuous line on the northern portion compared to the southern portion of the MCS (Fig. 7a). The southern portion, however, shows areas of higher $Z$ and greater convective coverage and organization compared to the same region 20 min earlier (Fig. 5c). By 0528 UTC (Fig. 7b), the leading line fits characteristics of well-defined leading-line/trailing stratiform MCSs (Houze et al. 1990) with a convex structure and large reflectivity gradients. In WRF $Z$, a similar evolution is observed with the continuous portion of the leading line developing southward and merging with more scattered convection. In the isochronal analysis, the southern 
portion of the leading line is observed to move eastward faster than the northern portion during surge B (Fig. 6).

In the forthcoming analyses, CFADs and statistical profiles are computed within the surge regions to examine MCS evolution from radar observations and the WRF simulation. In Figs. 5 and 7, the black dashed line shows the location of CFADs for each analysis time. For both radar and WRF data, CFAD regions were determined by outlining the leading edge of the MCS convective line where the surges and organizational changes occurred. Then, a second line is drawn rearward by $30 \mathrm{~km}$ (i.e., at a distance of $30 \mathrm{~km}$ rearward determined by a line orthogonal to the convective line slope) to include the primary convective line updrafts and downdrafts. While CFAD regions are determined subjectively, they enable a more focused analysis of microphysical, thermodynamic, and kinematic changes occurring in the surge regions.

\section{Analysis}

In this section, analyses of WSR-88D data and WRF simulations are presented for two surge periods: surge A occurred between 0410 and 0450 UTC and surge B occurred between 0510 and 0550 UTC.

\section{a. Surge A evolution}

During surge A, substantial changes in storm organization and microphysical characteristics are observed within the MCS. CFADs of radar reflectivity factor are shown for KFSD and WRF data in Fig. 8. It should be noted that CFADs from KFSD are shown only for altitudes where a radar elevation angle provides a beam height within $\pm 1 \mathrm{~km}$ of the entire CFAD region. ${ }^{2}$ The $Z$ decreases at mid- and upper levels during surge A for both KFSD (Figs. 8a-c) and WRF CFADs (Figs. 8d-f). At lower levels, $Z$ increases in the WRF simulation below the melting layer (about $4 \mathrm{~km}$ AGL; Figs. 8d-f) and also increases at $4 \mathrm{~km}$ AGL where KFSD WSR-88D data are available throughout surge A (Figs. 8a-c). As previous studies have noted (e.g., Wu et al. 2013), microphysical parameterizations in WRF tend to overestimate $Z$ values compared observations above the freezing level. Nonetheless, similar trends in the reflectivity profiles with height are observed indicating that similar processes are occurring even if the initial hydrometeor distributions exhibit some differences.

To further examine changes in hydrometeor distributions and radar variables, statistical profiles of radar and WRF variables are also computed for the same

\footnotetext{
${ }^{2}$ Since the MCS is moving toward KFSD, the CFAD analysis extends to lower altitudes at later times.
}

region in Fig. 9. KFSD and WRF mean $Z$ show a similar evolution to the CFADs during surge $A$, with decreasing $Z$ aloft, and higher $Z$ near the surface (Figs. 9a,b). KFSD specific differential phase $\left(K_{\mathrm{dp}}\right)$ and WRF rainwater mixing ratio are both examined because they are less sensitive to large particle sizes than radar reflectivity factor. KFSD mean $K_{\text {dp }}$ increases below the melting layer (Fig. 9c) and corresponds to an increase in WRF rainwater mixing ratio (Fig. 9d).

Substantial changes in graupel distributions aloft are evident in both radar and WRF data. Since radar data cannot be used to quantify graupel mixing ratios, PID data are compared to WRF graupel mixing ratios to provide qualitative comparisons of graupel distributions between KFSD and the WRF Model. It should be noted that the PID classification identifies the dominant radar scatterer type, and thus its relationship to WRF Model quantities is less direct than the previous comparisons. Using the NCAR PID data, the volume of the CFAD region identified as graupel or hail (or a mixture of these classes with rain) is computed. Since the Morrison scheme was not used with a hail option, we assume that the graupel class represents changes in larger ice particle distributions. The graupel volume from NCAR PID shows a decrease during surge A with the maximum graupel volume decreasing by approximately a factor of 2 . WRF mean graupel mixing ratio $q_{\text {graup }}$ also decreases during this period. Although the general trends in graupel agree between the radar and WRF data, the maximum value of PID volume occurs at a lower altitude compared to mean $q_{\text {graup }}$. It is possible that different hydrometeor types are the dominant scatterers at higher altitudes and graupel are still present, or the observed MCS contains higher graupel concentrations at lower altitudes compared to the model, or both.

In addition to microphysical changes, kinematic characteristics of the MCS evolve during surge A. For the surge A CFAD region, WRF statistics are computed as a function of height for zonal, meridional, updraft, and downdraft velocities in Figs. 10a-d, and relative humidity, potential temperature $\theta$, and virtual potential temperature $\theta_{V}$ in Figs. 10e-g. Between 0410 and 0450 UTC, the zonal wind component increases up to $4 \mathrm{~km}$ AGL and decreases at midlevels. The 90th percentile zonal winds also increase and exceed $20 \mathrm{~m} \mathrm{~s}^{-1}$ at $1 \mathrm{~km}$ AGL. The zonal wind component changes indicate the development of a mesoscale circulation with nearsurface rear-to-front flow and front-to-rear flow at midlevels. Mean and 90th percentile updraft speeds generally decrease throughout this period with the column-maximum mean or 90th percentile updraft speed decreasing by approximately a factor of 2 . Near the surface, however, 90th percentile updraft speeds decrease while the mean updraft remains approximately 

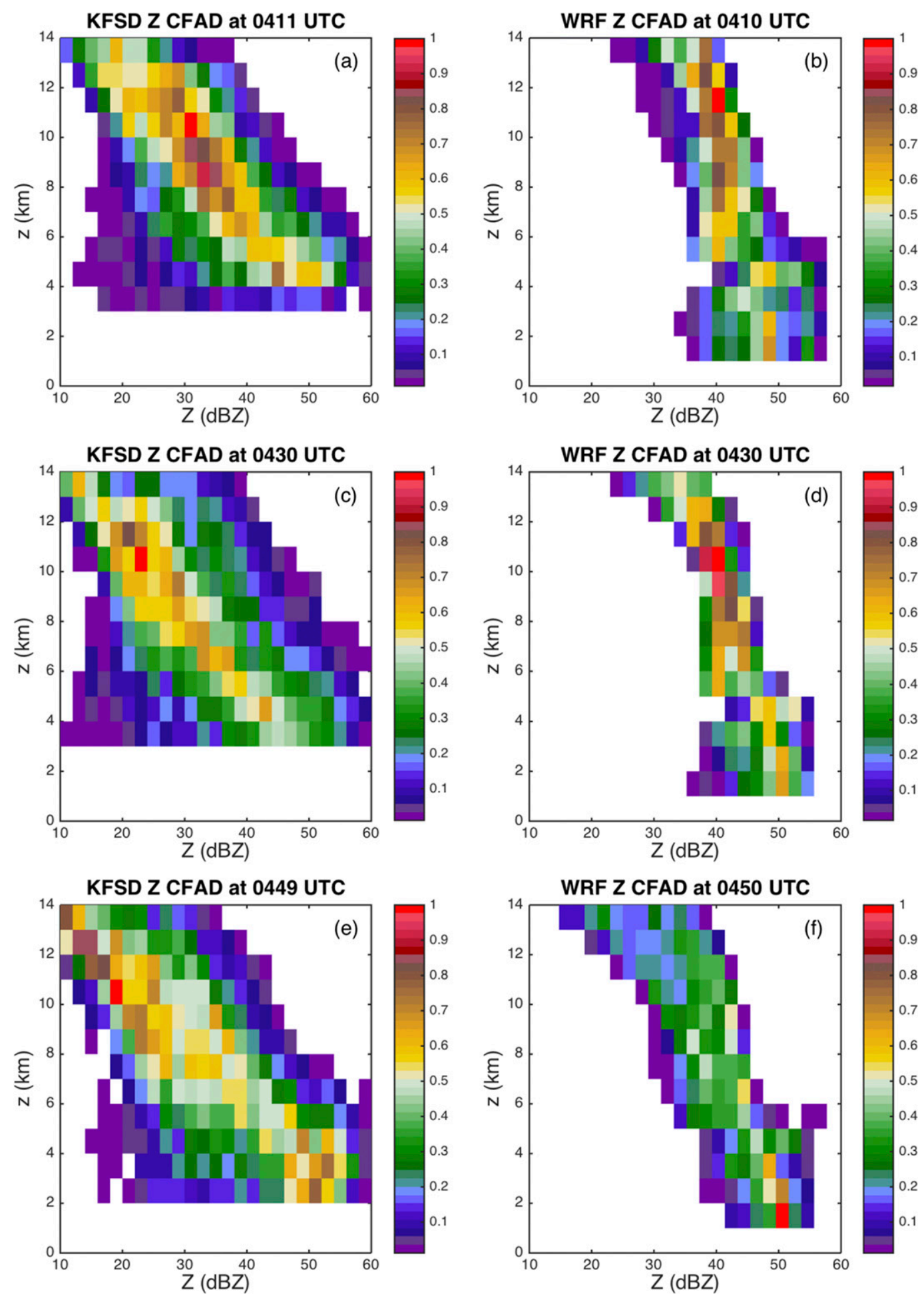

FIG. 8. Surge A CFADs of KFSD $Z$ at (a) 0411, (c) 0430, and (e) 0449 UTC and WRF $Z$ at (b) 0410, (d) 0430, and (f) 0450 UTC. These CFADs are computed for the surge regions shown by the black dashed areas in Figs. 5 and 7. 

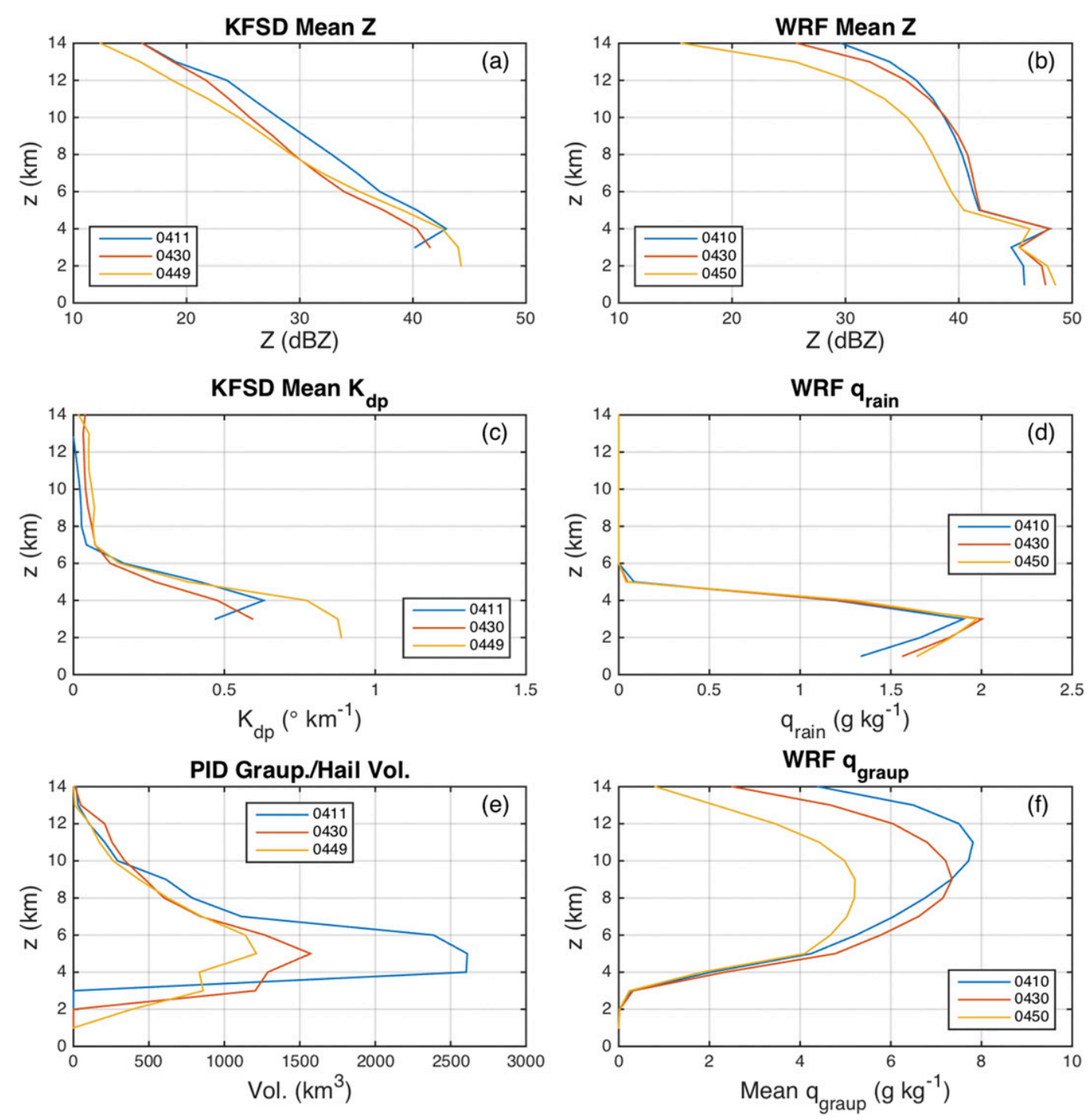

FIG. 9. Surge A profiles of KFSD (a) mean $Z(\mathrm{~dB} Z)$, (c) mean $K_{\mathrm{dp}}\left({ }^{\circ} \mathrm{km}^{-1}\right)$, (e) NCAR PID graupel volume $\left(\mathrm{km}^{3}\right)$, and mean values of WRF (b) $Z(\mathrm{dBZ})$, (d) rainwater mixing ratio $\left(q_{\text {rain }}, \mathrm{g} \mathrm{kg}^{-1}\right)$, and (f) graupel mixing ratio $\left(\mathrm{g} \mathrm{kg}^{-1}\right)$. Statistical profiles are computed for the surge regions shown by the black dashed areas in Figs. 5 and 7.

constant. Thus, the kinematic changes are largest for the most intense, near-surface updrafts. Downdraft intensity also increases by approximately a factor of 2 with the strongest mean low-level downdraft speed occurring at 0450 UTC $\left(-2.0 \mathrm{~m} \mathrm{~s}^{-1}\right)$.

During surge A, substantial changes in the thermodynamic environment occur at low levels. Between 0410 and 0450 UTC, relative humidity exhibits the largest increase near the surface, increasing from $73 \%$ to $81 \%$ at $1 \mathrm{~km}$. Relative humidity increases (decreases) below (above) about $3 \mathrm{~km}$ AGL (Fig. 10e), showing an increase in low-level moisture and a decrease in moisture at midlevels. Both $\theta$ and $\theta_{V}$ also decrease by about $3 \mathrm{~K}$ at $1 \mathrm{~km}$ AGL, and $\theta$ decreases over a 2.5 -km-deep layer
(Figs. 10f,g). At midlevels, thermodynamic changes are smaller magnitude compared to the near-surface layer.

To further examine where microphysical, kinematic, and thermodynamic changes occurred during surge A, line-averaged, vertical cross sections of the MCS are examined. Vertical cross sections of KFSD $Z$ are shown in Fig. 11, and WRF $Z$ and $q_{\text {graup }}$ are shown in Fig. 12. The averaged vertical cross sections are computed by taking a 45-km average normal to each point along the solid black lines in Figs. 5 and 7. At 0411 UTC, the KFSD $Z$ cross section shows the leading convective line at $X^{\prime}$ of $60-90 \mathrm{~km}$ (Fig. 5a) with $30-\mathrm{dB} Z$ echoes extending to $14 \mathrm{~km}$ AGL (Fig. 11a). Areas of isolated convection are evident ahead of the leading line ( $X^{\prime}$ between 100 and $160 \mathrm{~km}$ ), but this 

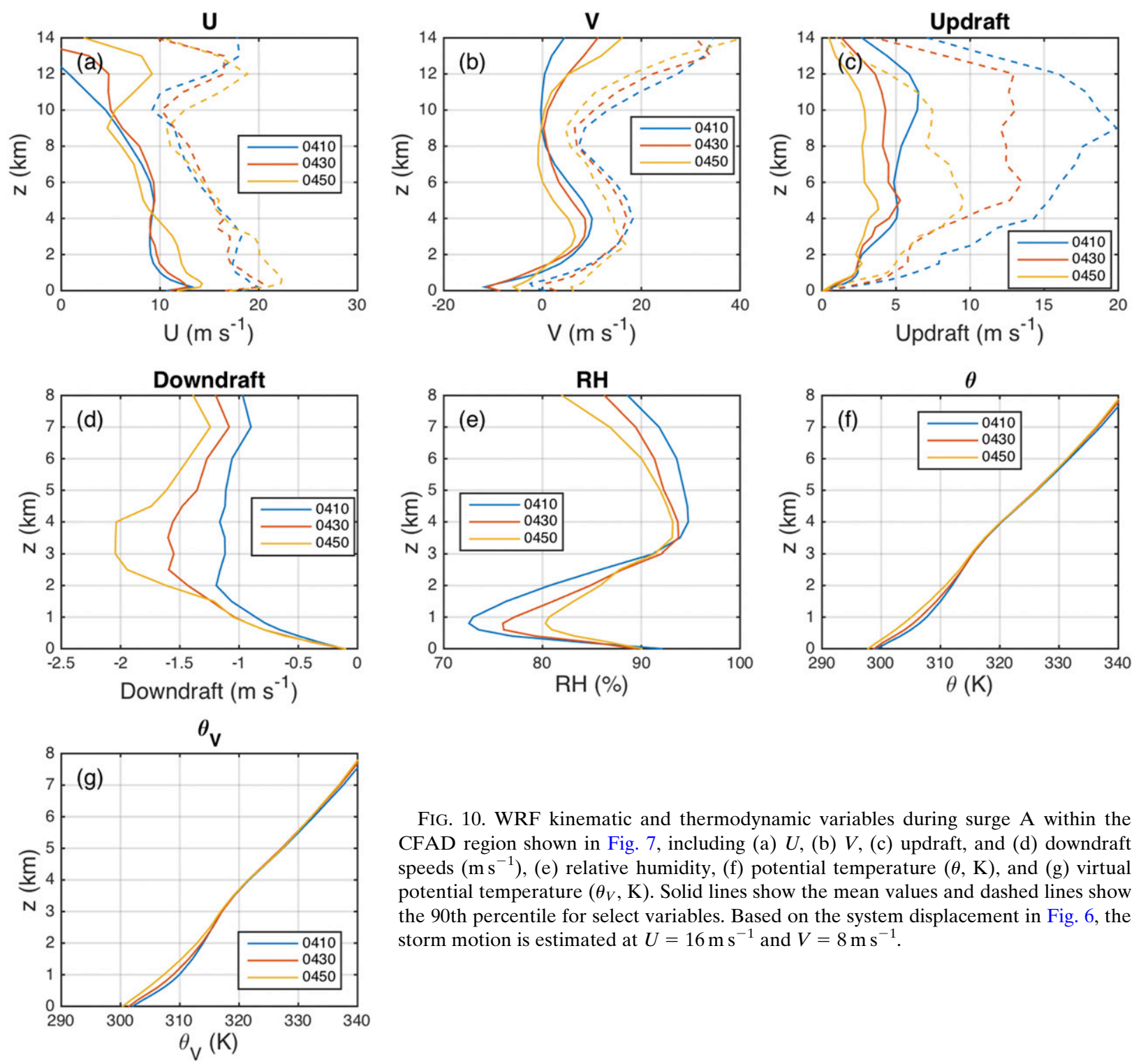

FIG. 10. WRF kinematic and thermodynamic variables during surge A within the CFAD region shown in Fig. 7, including (a) $U$, (b) $V$, (c) updraft, and (d) downdraft speeds $\left(\mathrm{m} \mathrm{s}^{-1}\right),(\mathrm{e})$ relative humidity, (f) potential temperature $(\theta, \mathrm{K})$, and $(\mathrm{g})$ virtual potential temperature $\left(\theta_{V}, \mathrm{~K}\right)$. Solid lines show the mean values and dashed lines show the 90th percentile for select variables. Based on the system displacement in Fig. 6, the storm motion is estimated at $U=16 \mathrm{~m} \mathrm{~s}^{-1}$ and $V=8 \mathrm{~m} \mathrm{~s}^{-1}$.

convection has a relatively shallow depth compared to the MCS leading line. Similarly, an intense, narrow convective line with an intense updraft with isolated updrafts ahead of the leading line is observed in the WRF cross section at 0410 UTC (Fig. 12a). Contours of $q_{\text {graup }}$ show a $30-50-\mathrm{km}$-wide region exceeding $4 \mathrm{~g} \mathrm{~kg}^{-1}$ extending to $14 \mathrm{~km}$ AGL, collocated with the most intense updraft (Fig. 12d). Beneath the graupel core, the most intense rainfall (e.g., yellow and red shading where $q_{\text {rain }}$ exceeds $1 \mathrm{~g} \mathrm{~kg}^{-1}$ ) is contained within a horizontal extent of $20 \mathrm{~km}$ of the leading edge of the convective line (Fig. 12d).

Between 0410 and 0450 UTC, the MCS transitions into a multicellular structure as it merges with nearby convective bands. By 0430 UTC, the $30-\mathrm{dBZ}$ echo top lowers within the MCS leading line, and the leading line has similar 30-dBZ echo tops compared to deepening convective cores ahead of the line (Fig. 11b). The WRF simulation also shows evidence of a developing multicellular structure. Ahead of the convective line, increased values of $Z$ are observed within a new updraft that develops near $X^{\prime}=180 \mathrm{~km}$ and extends above a height of $14 \mathrm{~km}$ (Figs. 12b,e). Moreover, the $1 \mathrm{~g} \mathrm{~kg}^{-1}$ graupel mixing ratio contour extends farther to the east, with the easternmost edge of the contour located approximately $60 \mathrm{~km}$ east of the center of the $4 \mathrm{~g} \mathrm{~kg}^{-1}$ contour at 0430 UTC compared to $45 \mathrm{~km}$ at 0410 UTC. High rainwater mixing ratios also cover a larger horizontal extent beneath the graupel core aloft with the $1 \mathrm{~g} \mathrm{~kg}^{-1}$ region extending rearward from the convective line by approximately $30 \mathrm{~km}$. Moreover, higher rainwater mixing ratios are 

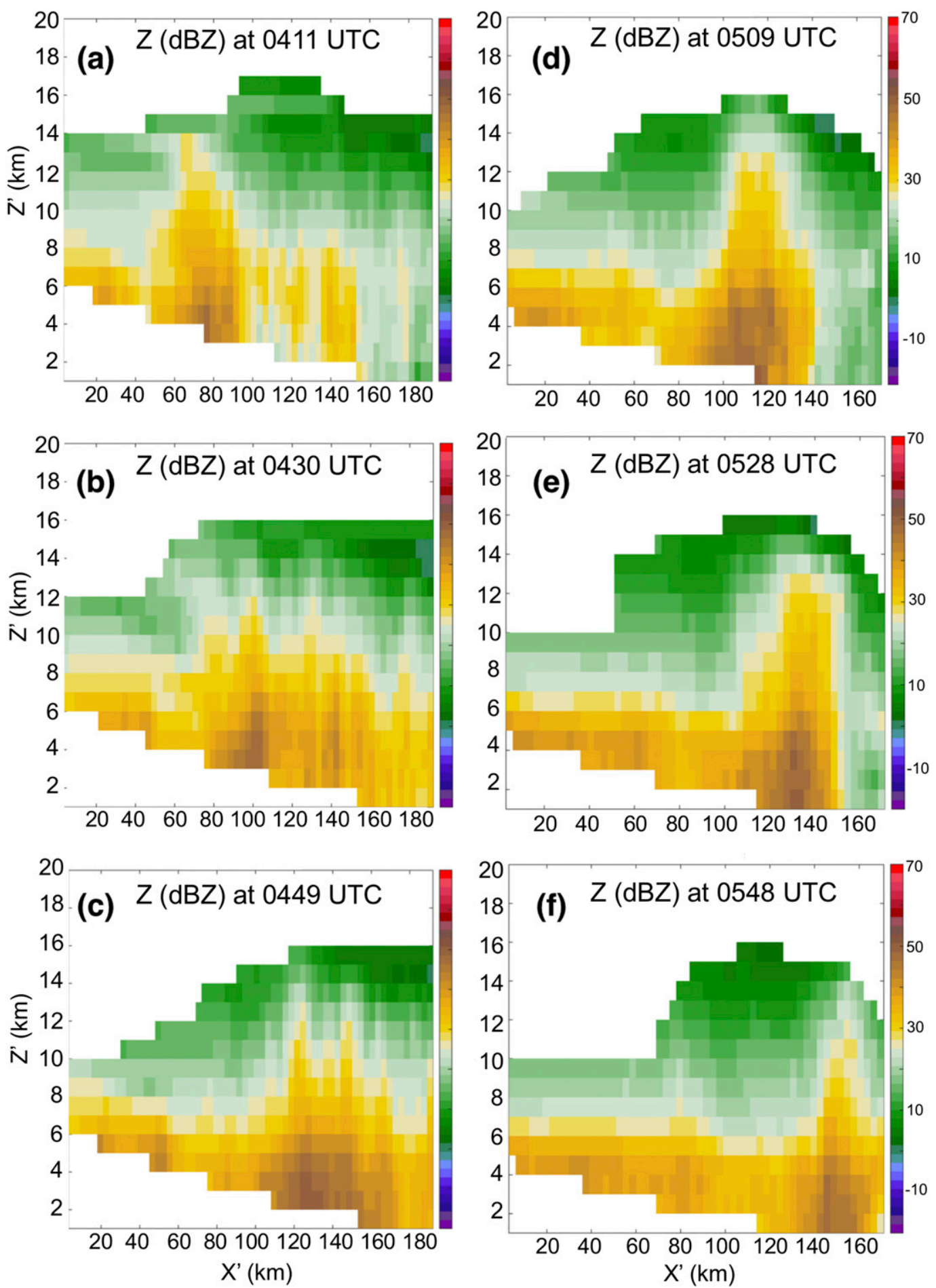

FIG. 11. KFSD cross sections of (a)-(f) mean $Z$ from 0411 to 0548 UTC. The vertical cross section is computed over a 45-km horizontal average normal to the solid black line shown in Fig. 5.

also observed ahead of the leading line beneath the developing convective cores.

As noted previously, $\theta$ and $\theta_{V}$ both decreased at low levels during surge A. The light blue contours in Fig. 12 show
$\theta_{V}$ perturbations of -2 and $-4 \mathrm{~K}$, and are used as an approximation of the cold pool. At $0430 \mathrm{UTC}, \theta_{V}$ perturbations show an expanded cold pool depth and intensity with the outermost $-2-\mathrm{K}$ contour reaching $3 \mathrm{~km} \mathrm{AGL}$ and 

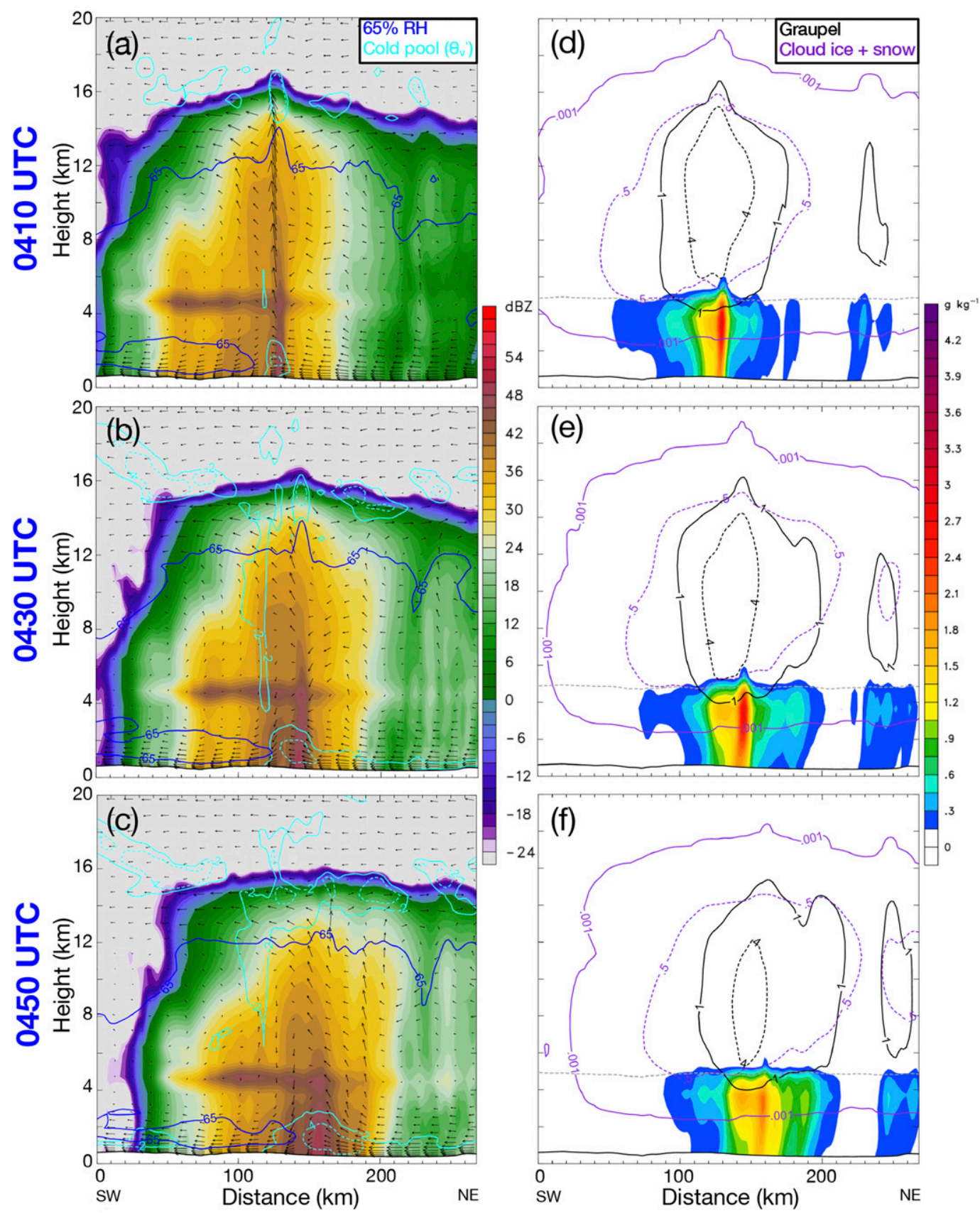

FIG. 12. Vertical cross sections of WRF data computed with a $45-\mathrm{km}$ horizontal average normal to the solid black line shown in Fig. 7 between 0410 and 0450 UTC. In (a)-(c), $Z$ is shown with the color shading, cold pool perturbation temperatures $\left(\theta_{V}^{\prime}\right)$ are shown with the light blue solid (dashed) lines for $-2(-4) \mathrm{K}$, the dark blue line shows a contour of $65 \%$ relative humidity, and vectors show winds in the cross-sectional plane. In (d)-(f), the color shading shows the rainwater mixing ratio $\left(\mathrm{g} \mathrm{kg}^{-1}\right)$, black solid (dashed) contours show graupel mixing ratio at 1 (4) $\mathrm{g} \mathrm{kg}^{-1}$, and the purple contours are combined mixing ratio of cloud ice and snow at $0.001(0.5) \mathrm{g} \mathrm{kg}^{-1}$.

the $-4-K$ contour enclosing a larger volume compared to 0410 UTC. The most intense cooling occurs beneath the region of highest rainwater content. In addition to cooling within the MCS, increased cooling occurs ahead of the primary convective line, associated with the deepening convection and/or nocturnal cooling. It is interesting to note that although mean low-level relative humidity increases in the CFAD region, dry air continues to intrude into the downdraft region as the $65 \%$ relative humidity contour remains within $10-20 \mathrm{~km}$ of the convective core. 
Thus, with the most intense downdraft penetrating this subsaturated layer, the cold pool thermodynamic characteristics within this downdraft region have components of both subsidence warming and evaporative cooling, perhaps leading to smaller changes in cold pool temperatures compared to the primary convective downdraft. Within the most intense downdraft $\left(X^{\prime}=125 \mathrm{~km}\right), Z$ increases slightly toward the surface while rainwater mixing ratio decreases. Although a combination of microphysical processes are likely occurring, evaporation would reduce the number of small drops compared to the number of large drops leading to a more pronounced effect on rainwater mixing ratio compared to $Z$. However, the increase in $Z$ suggests that other microphysical processes remain important (e.g., coalescence) since evaporation alone would decrease $Z$.

At 0450 UTC, two deep convective cores are evident in the KFSD vertical cross sections at $X^{\prime}=120$ and $145 \mathrm{~km}$ (Fig. 11c). The highest $Z$ values are beneath and slightly ahead of the rearward convective core $\left(X^{\prime}=120\right.$ $130 \mathrm{~km}$ ). Vertical cross sections of WRF $Z$ show a similar configuration of the MCS with two deep convective cores and updrafts separated by approximately $30 \mathrm{~km}$, and the highest $Z$ values beneath the rearward convective core (Fig. 12c). The $4 \mathrm{~g} \mathrm{~kg}^{-1}$ graupel contour covers a reduced areal extent while the $1 \mathrm{~g} \mathrm{~kg}^{-1}$ graupel contour continues to expand eastward and increase in height within the convective core at $X^{\prime}=190 \mathrm{~km}$ (Fig. 12f). Reduced graupel production within the MCS leading line may result from the reduced updraft velocities throughout most of the convective line surge region (Fig. 10c); however, some new regions of graupel development are observed associated with new updrafts. The $-2-\mathrm{K} \theta_{V}^{\prime}$ contour expands rearward near the surface compared to 0430 UTC, and also increases in altitude ahead of the MCS (Fig. 12f). The $-4-\mathrm{K} \theta_{V}^{\prime}$ contour extends about $25 \mathrm{~km}$ ahead of the maximum near-surface $Z$ in the rearward convective core, suggesting an intensification of the cold pool ahead of the original MCS leading line beneath the forward convective core.

The development of the cold pool farther east introduces an evolution similar to the discrete propagation events discussed by Fovell et al. (2006). In their simulations, the new convection merges with the old convection and weakens the primary convective line, and new convection ahead of the MCS develops a cold pool sufficient to produce a jump in the MCS gust front position. During surge A, a similar process is observed where new convection develops ahead of the main line, the MCS cold pool expands eastward, and the primary convective line updraft weakens. By 0450 UTC, the most intense updraft along the cross section is observed above the leading edge of the $-4-\mathrm{K} \theta_{V}$ contour, indicating that the cold pool has expanded eastward ahead of the main convective updraft. Similarities and differences between the Fovell et al. (2006) findings and the evolution noted here will be discussed in the conclusions.

\section{b. Surge B evolution}

During surge $\mathrm{B}$, the MCS reorganizes and develops characteristics of a mature MCS, and the southern portion of the MCS leading line moves eastward faster than the northern portion (Figs. 7a-c). For surge B, 45-km line-averaged vertical cross sections of KFSD $Z$ are shown in the right column of Fig. 11 and 45-km lineaveraged vertical cross sections of WRF data are shown in Fig. 13. At 0509 UTC (Fig. 11d), KFSD $Z$ shows a more organized MCS compared to 0430 and 0449 UTC. From $0.5^{\circ}$ elevation $Z$ (Fig. 7a), the southern portion of the primary convective line exhibits less continuous structure in $Z$ with banded and multicellular structures compared to the northern portion. Similar to the radar observations, the vertical cross section of WRF data at 0510 UTC (Fig. 13a) shows a more organized system with an intense convective core and substantial trailing stratiform rain.

During surge B, the MCS develops microphysical structure expected of a mature MCS. By 0528 and 0548 UTC, the MCS exhibits a well-defined leading line with $30-\mathrm{dB} Z$ KFSD $Z$ extending to $12-13 \mathrm{~km}$, and an extensive region of robust trailing stratiform rain is present (Figs. 11e,f). A similar MCS structure is observed in WRF $Z$ (Figs. 13b,c), including a larger region of high graupel mixing ratio in the convective core compared to 0450 UTC (Figs. 13e,f). Although new convection develops ahead of the MCS (Figs. 7d,f and 13e,f), it does not appear to adversely affect the MCS structure during surge B.

A mesoscale circulation in the surge $\mathrm{B}$ region develops with enhanced regions of rear-to-front flow near the surface and front-to-rear flow aloft (Fig. 14a). The increase in 90th percentile $U$ is consistent with the development of a rear-inflow jet, which becomes most intense at $2-3 \mathrm{~km}$ AGL at 0530-0550 UTC. Consistent with the MCS reintensification, updraft intensity is also larger during surge B compared to 0450 UTC (cf. Figs. 14c and 9c). Mean downdraft velocity magnitudes also decrease during surge B compared to 0450 UTC during surge A (Fig. 14d), and the intense downdraft on the rear side of the leading line (Fig. 12c) weakens substantially (Fig. 13a).

The MCS thermodynamic characteristics exhibit smaller changes during surge B compared to surge A. A substantial temporal change in mean relative humidity, $\theta$, and $\theta_{V}$ is not observed within the surge B CFAD regions (Figs. 14e-g). In a cross-sectional perspective, the cold pool depth increases slightly with the maximum altitude of the $-2-\mathrm{K} \theta_{V}^{\prime}$ contour increasing from 3 to $4 \mathrm{~km}$ AGL. The horizontal extent of the $-4-\mathrm{K}$ contour also extends 

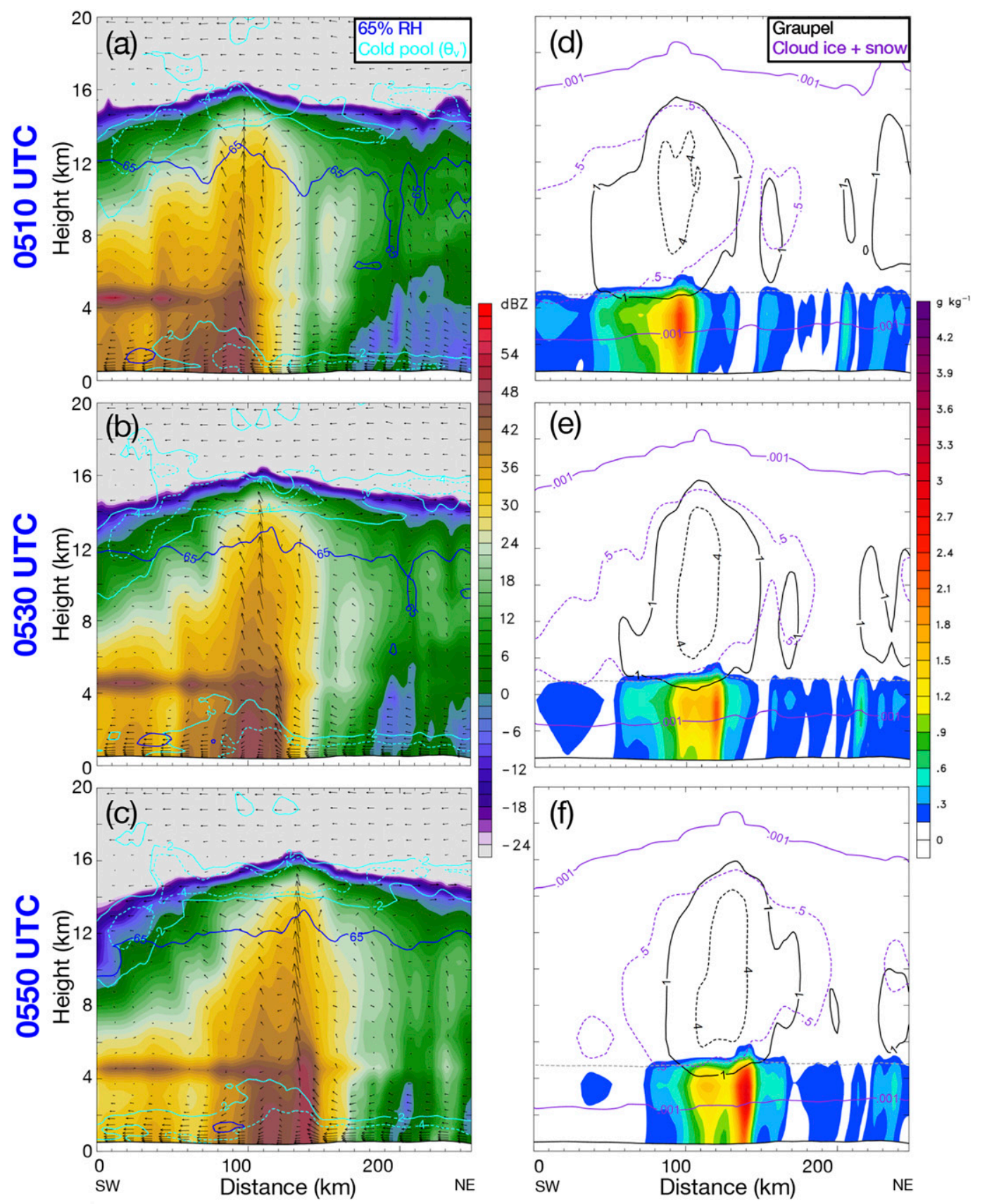

FIG. 13. Vertical cross sections of WRF data between 0510 and 0550 UTC with the same contours and shadings as in Fig. 12. The vertical cross section is computed with a $45-\mathrm{km}$ horizontal average normal to the solid black line shown in Fig. 7.

farther rearward from the leading edge of the convective line (Figs. 13a-c). In contrast to the surge A cross sections, the $65 \%$ relative humidity contour has also decreased in areal extent at low levels (e.g., in the lowest $3 \mathrm{~km}$ ), indicating a reduced of region dry air behind the convective line. Ahead of the convective line, the near-surface air continues to cool as a consequence of evaporative cooling from convection developing ahead of the primary convective line or nocturnal cooling, or both.

\section{Conclusions}

This study documents the transitional stages of a mature MCS convective line which evolves from a well-defined 

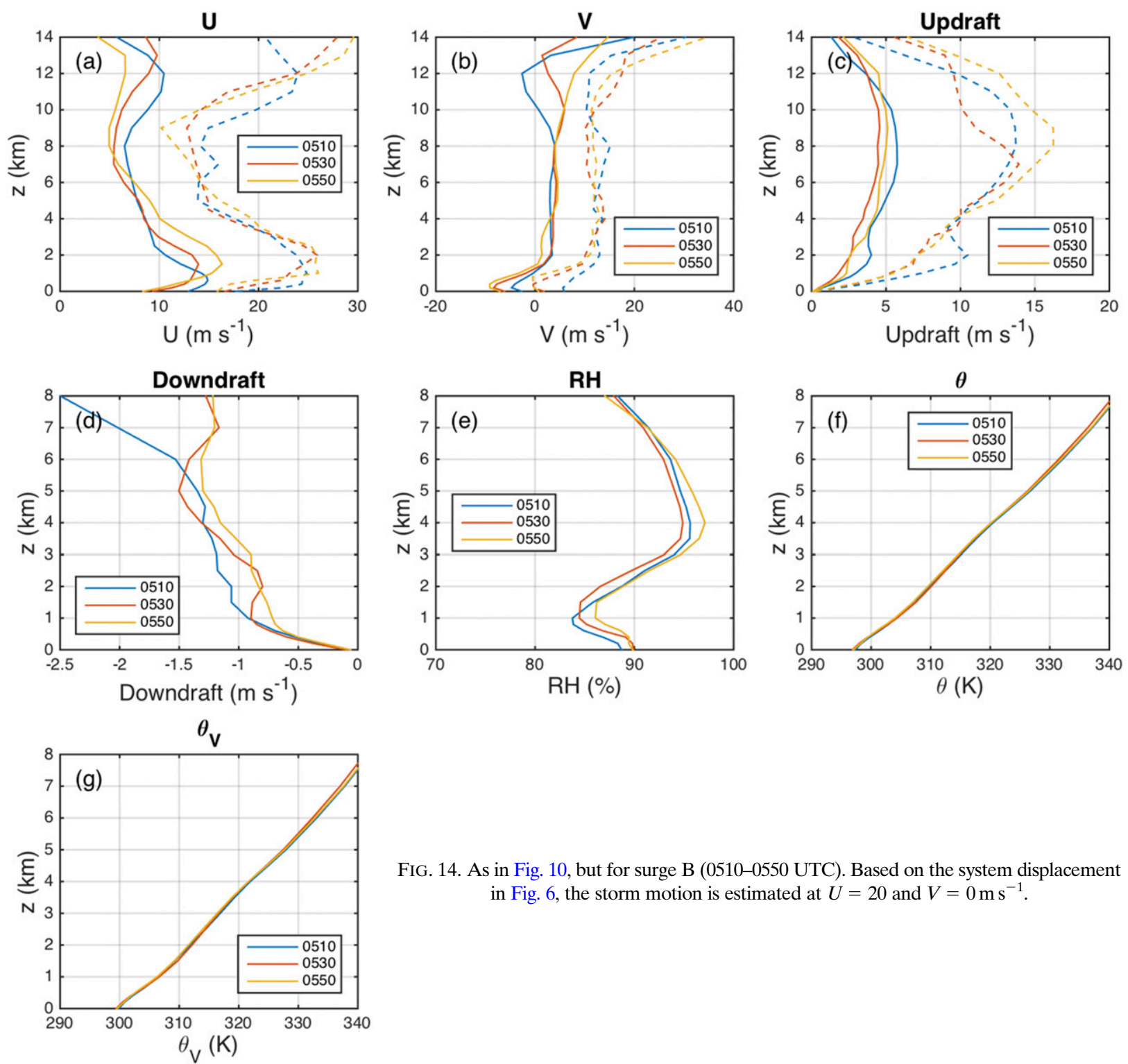

FIG. 14. As in Fig. 10, but for surge B (0510-0550 UTC). Based on the system displacement in Fig. 6, the storm motion is estimated at $U=20$ and $V=0 \mathrm{~m} \mathrm{~s}^{-1}$.

leading line to a multicellular structure (surge A), and then reorganizes back to a well-defined leading line (surge B). During these transitional stages, a segment of the convective line propagates faster than the mean line motion. The transition to multicellular structure occurs as the northern portion of the convective line intersects two parallel bands of convection near the cold front, and the northern portion accelerates eastward relative to the southern portion of the leading line.

During surge A, several microphysical changes are observed in both the radar data and WRF simulations. Reflectivity decreases and graupel concentrations are reduced above the freezing level, while KFSD nearsurface reflectivity and $K_{\mathrm{dp}}$ increase corresponding to an increase in WRF $Z$ and rainwater mixing ratio. In addition to microphysical changes, kinematic and thermodynamic changes are evident in the WRF simulation. Mean and 90th percentile updraft velocities decrease by approximately a factor of 2 , and may be a contributing factor to fallout and reduced production of larger ice particles as evidenced by lower $Z$ aloft. Near-surface zonal winds increase substantially, and mean downdraft behind the convective line intensifies. The strongest downdraft develops behind the primary convective line, causing increased hydrometeor loading and evaporative cooling. These processes likely contribute to the development of a more intense and deeper cold pool. 
The MCS regains a mature appearance with a convexshaped, leading-line and extensive trailing-stratiform region during surge $B$. The WRF simulation shows an intense updraft region with a collocated column of high $Z$ and $q_{\text {graupel }}$ aloft, consistent with radar observations of an upright column of high $Z$. Moreover, mesoscale flow patterns continue to develop with a stronger rear-inflow jet and zonal wind speeds approaching severe wind criteria. The highest 90th percentile zonal wind speeds are observed between 0450 and 0550 UTC, which coincides with several severe wind reports (Fig. 6).

Similar to idealized simulations by Rotunno et al. (1988) and Weisman (1993), the MCS updraft intensity weakens as the cold pool and associated circulation intensified during surge A. Weisman (1993) found that the elevated rear-inflow jet helped to offset the increased horizontal vorticity of the cold pool occurring during the previous stage, allowing for deeper lifting since the environmental and cold pool horizontal vorticities were near optimal balance again [see Fig. 14 in Weisman (1993)]. During surge $B$, a similar process may have occurred since the elevated rear-inflow jet intensified while cold pool intensity did not change. An alternative explanation is that during the merger (surge A), storm organization and updraft buoyancy decreased as the MCS inflow was disrupted. After the merger completed (surge B), the MCS became better organized with a single updraft along the leading edge and updraft intensity increased.

In the subsequent discussion, the chief findings of the study are presented and comparisons to idealized studies are discussed:

1) A discrete propagation event is observed during surge A, leading to enhanced forward propagation of a convective line segment. During surge A, the leading edge of the cold pool moves forward from the leading convective line to the new convection initiation ahead of the MCS. After the cold pool surges forward, the rearward convective updraft weakens and the MCS along-line cross section exhibits a multicellular structure. The radar and WRF simulation evolution is similar to Fovell et al. (2006) wherein the convective line and cold pool gust front position moves forward abruptly when the new convection's cold pool intensifies. An important difference between these simulations and those of Fovell et al. (2006) is the presence of a different convection initiation mechanism. In the Fovell et al. (2006) simulations, they found that gravity waves initiated isolated convection ahead of the primary convective line, while in this case, new convection forms in bands oriented orthogonally to the primary convective line and these bands subsequently merge with the primary convective line.
2) The observed and simulated MCS evolution exhibits similarities and differences to idealized simulations of MCSs. The MCS evolution during surges A and B broadly resembles the evolution of the idealized simulations by Weisman (1993). In their simulations, the cold pool intensifies and the convective line weakens due to increased system tilt. In the present study, a weakening of the MCS is observed as the cold pool intensifies. A difference between the idealized case and the real case examined herein is the observed merger with the frontal convective band. It is likely that discrete propagation during surge A contributed to a greater acceleration of the MCS convective line than would have occurred otherwise. During surge B, the MCS evolves similarly to the Weisman (1993) simulation period during which the rear inflow jet becomes elevated and intensifies and the MCS becomes better organized (120-180 min). An important difference between this study and Weisman (1993) is that the WRF MCS propagation speed did not increase monotonically. In the present study, segments within the convective line accelerate while the mean MCS propagation speed only increases slightly. In summary, while the MCS simulated herein uses real data boundary conditions and more sophisticated physics parameterizations compared to past idealized simulations, the idealized and WRF simulations produce a similar evolution in MCS system-relative flow patterns and organization. However, the discrete propagation event and associated microphysical feedbacks lead to nonuniform accelerations of the convective line.

3) The simulated MCS herein exhibits similar behavior to the idealized simulations of Parker (2008). The MCS remained primarily surface based, consistent with their simulations with limited nocturnal cooling. The Sioux Falls, South Dakota, surface observations, representative of the MCS inflow region, only cooled by $4-5 \mathrm{~K}$ between 0400 and 0600 UTC compared to the daytime maximum temperature. Similar to their findings in a limited cooling simulation, the WRF simulation did not proceed to the stalling stage, but most closely resembled their strengthening and quasisteady stages. The surge A period is similar to the strengthening phase noted by Parker (2008) during which cold pool intensity and MCS system speed increase. However, in the present study the MCS becomes disorganized as a consequence of interactions with nearby convection, while in the Parker (2008) simulations the MCS became better organized. Moreover, the MCS system speed increases primarily within the northern segment of the convective line, but the overall MCS system speed did not increase substantially. Toward the end of surge B, the MCS is 
similar to the quasi-steady stage from Parker (2008) with WRF simulations showing a primarily surfacebased MCS with nearly constant system motion.

4) The study illustrates techniques to evaluate microphysical processes in WRF real cases using dualpolarization radar data from NEXRAD radars, including CFAD and statistical analyses. Close agreement is observed between dual-polarization radar and WRF data during both surges, increasing confidence that the microphysical processes occurring in WRF simulations represent observed processes. The PID comparisons also illuminate a method to compare how specific hydrometeor classes evolve since quantitative retrievals of ice and mixedphase particle size distributions are not easily obtained from dual-polarization radar data.

During the PECAN experiment, MCS cases were observed by a suite of instruments including mobile radars, mobile mesonets and sounding units, aircraft, and PECAN Integrated Sounding Arrays. The MCS cases cover a range of different organizational structures and life cycle stages, and rapid forward propagation events were observed in some MCS cases but not others. Thus, these datasets enable an exploration of what causes rapid forward propagation events. Since these events occurred within different MCS organizational structures, it is possible that different mechanisms for rapid forward propagation onset will be identified. The presence of numerous observational datasets also enables more direct comparisons between observational datasets and WRF simulations, including dual-polarization radar comparisons.

Acknowledgments. This study was conducted while the authors were supported by the National Center for Atmospheric Research (NCAR) Advanced Study Program. The authors are grateful to EOL for their support during the PECAN field project, and for providing mosaic images for the study. We also thank the PECAN participants for their hard work collecting numerous datasets, including the sounding data used in this study. This work benefitted from numerous discussions with EOL and MMM scientists during the authors' ASP postdoctoral fellowship, especially with Tammy Weckwerth, George Bryan, and Stan Trier. Stan Trier and Tammy Weckwerth also provided very helpful reviews of an earlier version of this manuscript. The authors also appreciate comments from two anonymous reviewers and Pam Heinselman that helped improve the manuscript. The authors thank Mike Dixon for providing the NCAR PID data for this case. We would like to acknowledge high-performance computing support for the WRF simulations from Yellowstone (ark:/85065/d7wd3xhc) provided by NCAR's
Computational and Information Systems Laboratory, sponsored by the National Science Foundation.

\section{REFERENCES}

Biggerstaff, M. I., and R. A. Houze, 1991: Kinematic and precipitation structure of the 10-11 June 1985 squall line. Mon. Wea. Rev., 119, 3034-3065, doi:10.1175/1520-0493(1991)119<3034: KAPSOT $>2.0 . \mathrm{CO} ; 2$.

Bluestein, H. B., and M. H. Jain, 1985: Formation of mesoscale lines of precipitation: Severe squall lines in Oklahoma during the spring. J. Atmos. Sci., 42, 1711-1732, doi:10.1175/ 1520-0469(1985)042<1711:FOMLOP > 2.0.CO;2.

Braun, S. A., and R. A. Houze, 1995: Melting and freezing in a mesoscale convective system. Quart. J. Roy. Meteor. Soc., 121, 55-77, doi:10.1002/qj.49712152104.

Chen, F., and J. Dudhia, 2001: Coupling an advanced land surfacehydrology model with the Penn State-NCAR MM5 modeling system. Part I: Model implementation and sensitivity. Mon. Wea. Rev., 129, 569-585, doi:10.1175/1520-0493(2001)129<0569: CAALSH $>2.0 . \mathrm{CO} ; 2$.

Corfidi, S. F., 2003: Cold pools and MCS propagation: Forecasting the motions of downwind-developing MCSs. Wea. Forecasting, 18, 997-1017, doi:10.1175/1520-0434(2003)018<0997: $\mathrm{CPAMPF}>2.0 . \mathrm{CO} ; 2$

_ J. H. Merritt, and J. M. Fritsch, 1996: Predicting the movement of mesoscale convective complexes. Wea. Forecasting, 11, 41-46, doi:10.1175/1520-0434(1996)011<0041:PTMOMC>2.0.CO;2.

Crook, N. A., and M. W. Moncrieff, 1988: The effect of large-scale convergence on the generation and maintenance of deep moist convection. J. Atmos. Sci., 45, 3606-3624, doi:10.1175/ 1520-0469(1988)045<3606:TEOLSC > 2.0.CO;2.

Dudhia, J., 1989: Numerical study of convection observed during the winter monsoon experiment using a mesoscale twodimensional model. J. Atmos. Sci., 46, 3077-3107, doi:10.1175/ 1520-0469(1989)046<3077:NSOCOD > 2.0.CO;2.

Fovell, R. G., and Y. Ogura, 1989: Effects of vertical wind shear on numerically simulated multicell storm structure. J. Atmos. Sci., 46, 3144-3176, doi:10.1175/1520-0469(1989)046<3144: EOVWSO $>2.0 . \mathrm{CO} ; 2$.

— G. L. Mullendore, and S.-H. Kim, 2006: Discrete propagation in numerically simulated nocturnal squall lines. Mon. Wea. Rev., 134, 3735-3752, doi:10.1175/MWR3268.1.

Fritsch, J. M., R. J. Kane, and C. R. Chelius, 1986: The contribution of mesoscale convective weather systems to warm season precipitation in the United States. J. Climate Appl. Meteor., 25, 1333-1345, doi:10.1175/1520-0450(1986)025<1333:TCOMCW >2.0.CO;2.

Geerts, B., and Coauthors, 2017: The 2015 Plains Elevated Convection at Night field project. Bull. Amer. Meteor. Soc., 98, 767-786, doi:10.1175/BAMS-D-15-00257.1.

Homeyer, C. R., and M. R. Kumjian, 2015: Microphysical characteristics of overshooting convection from polarimetric radar observations. J. Atmos. Sci., 72, 870-891, doi:10.1175/JAS-D-13-0388.1.

Hong, S.-Y., Y. Noh, and J. Dudhia, 2006: A new vertical diffusion package with an explicit treatment of entrainment processes. Mon. Wea. Rev., 134, 2318-2341, doi:10.1175/MWR3199.1.

Houze, R. A., 2004: Mesoscale convective systems. Rev. Geophys., 42, RG4003, doi:10.1029/2004RG000150.

_ B B. F. Smull, and P. Dodge, 1990: Mesoscale organization of springtime rainstorms in Oklahoma. Mon. Wea. Rev., 118, 613654, doi:10.1175/1520-0493(1990)118<0613:MOOSRI >2.0.CO;2.

Johns, R. H., 1993: Meteorological conditions associated with bow echo development in convective storms. Wea. 
Forecasting, 8, 294-299, doi:10.1175/1520-0434(1993)008<0294: MCAWBE $>2.0 . C O ; 2$.

Kain, J. S., and J. M. Fritsch, 1993: Convective parameterization for mesoscale models: The Kain-Fritsch scheme. The Representation of Cumulus Convection in Numerical Models, Meteor. Monogr., No. 46, Amer. Meteor. Soc., 165-170.

Leary, C. A., and R. A. Houze, 1979: Melting and evaporation of hydrometeors in precipitation from the anvil clouds of deep tropical convection. J. Atmos. Sci., 36, 669-679, doi:10.1175/ 1520-0469(1979)036<0669:MAEOHI >2.0.CO;2.

Mlawer, E. J., S. J. Taubman, P. D. Brown, M. J. Iacono, and S. A. Clough, 1997: Radiative transfer for inhomogeneous atmospheres: RRTM, a validated correlated-k model for the longwave. J. Geophys. Res., 102, 16 663-16682, doi:10.1029/97JD00237.

Morrison, H., J. A. Curry, and V. I. Khvorostyanov, 2005: A new double-moment microphysics parameterization for application in cloud and climate models. Part I: Description. J. Atmos. Sci., 62, 1665-1677, doi:10.1175/JAS3446.1.

Parker, M. D., 2008: Response of simulated squall lines to low-level cooling. J. Atmos. Sci., 65, 1323-1341, doi:10.1175/2007JAS2507.1.

_ , and R. H. Johnson, 2000: Organizational modes of midlatitude mesoscale convective systems. Mon. Wea. Rev., 128, 3413-3436, doi:10.1175/1520-0493(2001)129<3413:OMOMMC>2.0.CO;2.

Rasmussen, K. L., M. M. Chaplin, M. D. Zuluaga, and R. A. Houze Jr., 2016: Contribution of extreme convective storms to rainfall in South America. J. Hydrometeor., 17, 353-367, doi:10.1175/JHM-D-15-0067.1.

Rotunno, R., J. B. Klemp, and M. L. Weisman, 1988: A theory for strong, long-lived squall lines. J. Atmos. Sci., 45, 463-485, doi:10.1175/1520-0469(1988)045<0463:ATFSLL>2.0.CO;2.

Rutledge, S. A., R. A. Houze Jr., M. I. Biggerstaff, and T. Matejka, 1988: The Oklahoma-Kansas Mesoscale Convective System of 10-11 June 1985: Precipitation structure and single-Doppler radar analysis. Mon. Wea. Rev., 116, 1409-1430, doi:10.1175/ 1520-0493(1988)116<1409:TOMCSO > 2.0.CO;2.

Ryzhkov, A. V., and D. S. Zrnić, 1994: Precipitation observed in Oklahoma mesoscale convective systems with a polarimetric radar. J. Appl. Meteor., 33, 455-464, doi:10.1175/ 1520-0450(1994)033<0455:POIOMC > 2.0.CO;2.

$\longrightarrow$, and - 1995: Precipitation and attenuation measurements at a 10-cm wavelength. J. Appl. Meteor., 34, 2121-2134, doi:10.1175/1520-0450(1995)034<2120:PAAMAA > 2.0.CO;2.

— S. E. Giangrande, V. M. Melnikov, and T. J. Schuur, 2005: Calibration issues of dual-polarization radar measurements. J. Atmos. Oceanic Technol., 22, 1138-1155, doi:10.1175/JTECH1772.1.

Schumacher, R. S., and R. H. Johnson, 2005: Organization and environmental properties of extreme-rain-producing mesoscale convective systems. Mon. Wea. Rev., 133, 961-976, doi:10.1175/MWR2899.1.

Skamarock, W. C., and J. B. Klemp, 2008: A time-split nonhydrostatic atmospheric model for weather research and forecasting applications. J. Comput. Phys., 227, 3465-3485, doi:10.1016/j.jcp.2007.01.037.

_- , and Coauthors, 2008: A description of the Advanced Research WRF version 3. NCAR Tech. Note NCAR/ TN-475+STR, 113 pp., doi:10.5065/D68S4MVH.

Smith, B. T., T. E. Castellanos, A. C. Winters, C. M. Mead, A. R. Dean, and R. L. Thompson, 2013: Measured severe convective wind climatology and associated convective modes of thunderstorms in the contiguous United States, 2003-09. Wea. Forecasting, 28, 229-236, doi:10.1175/WAF-D-12-00096.1.

Smull, B. F., and R. A. Houze, 1985: A midlatitude squall line with a trailing region of stratiform rain: Radar and satellite observations. Mon. Wea. Rev., 113, 117-133, doi:10.1175/ 1520-0493(1985)113<0117:AMSLWA > 2.0.CO;2.

$\longrightarrow$, and — 1987: Rear inflow in squall lines with trailing stratiform precipitation. Mon. Wea. Rev., 115, 2869-2889, doi:10.1175/1520-0493(1987)115<2869:RIISLW>2.0.CO;2.

Szeto, K. K., C. A. Lin, and R. E. Stewart, 1988a: Mesoscale circulations forced by melting snow. Part I: Basic simulations and dynamics. J. Atmos. Sci., 45, 1629-1641, doi:10.1175/ 1520-0469(1988)045<1629:MCFBMS > 2.0.CO; 2 .

— R. E. Stewart, and C. A. Lin, 1988b: Mesoscale circulations forced by melting snow. Part II: Applications to meteorological features. J. Atmos. Sci., 45, 1642-1650, doi:10.1175/ 1520-0469(1988)045<1642:MCFBMS>2.0.CO;2.

Tao, W.-K., J. R. Scala, B. Ferrier, and J. Simpson, 1995: The effect of melting processes on the development of a tropical and midlatitude squall line. J. Atmos. Sci., 52, 1934-1948, doi:10.1175/ 1520-0469(1995)052<1934:TEOMPO > 2.0.CO;2.

Thompson, G., R. M. Rasmussen, and K. Manning, 2004: Explicit forecasts of winter precipitation using an improved bulk microphysics scheme. Part I: Description and sensitivity analysis. Mon. Wea. Rev., 132, 519-542, doi:10.1175/ 1520-0493(2004)132<0519:EFOWPU>2.0.CO;2.

Trapp, R. J., S. A. Tessendorf, E. S. Godfrey, and H. E. Brooks, 2005: Tornadoes from squall line and bow echoes. Part I: Climatological distribution. Wea. Forecasting, 20, 23-34, doi:10.1175/WAF-835.1.

UCAR/NCAR Earth Observing Laboratory, 2016: EOL field catalog (1995-present). Accessed 25 September 2016, doi:10.5065/ D6SQ8XFB.

Vivekanandan, J., S. M. Ellis, R. Oye, D. S. Zrnić, A. V. Ryzhkov, and J. Straka, 1999: Cloud microphysics retrieval using S-band dual-polarization radar measurements. Bull. Amer. Meteor. Soc., 80, 381-388, doi:10.1175/1520-0477(1999)080<0381: CMRUSB $>2.0 . \mathrm{CO} ; 2$.

Weisman, M. L., 1993: The genesis of severe, long-lived bow echoes. J. Atmos. Sci., 50, 645-670, doi:10.1175/1520-0469(1993)050<0645: TGOSLL $>2.0$. CO;2.

Wu, D., X. Dong, B. Xi, Z. Feng, A. Kennedy, G. Mullendore, M. Gilmore, and W.-K. Tao, 2013: Impacts of microphysical scheme on convective and stratiform characteristics in two high precipitation squall line events. J. Geophys. Res. Atmos., 118, 11 119-11 135, doi:10.1002/jgrd.50798.

Yuter, S. E., and R. A. Houze, 1995: Three-dimensional kinematic and microphysical evolution of Florida cumulonimbus. Part II: Frequency distributions of vertical velocity, reflectivity, and differential reflectivity. Mon. Wea. Rev., 123, 1941-1963, doi:10.1175/1520-0493(1995)123<1941:TDKAME>2.0.CO;2.

Ziegler, C. L., M. Coniglio, M. Parker, and R. Schumacher, 2016: CSU/NCSU/NSSL MGAUS radiosonde data, version 3.0. UCAR/NCAR Earth Observing Laboratory, accessed 16 October 2016, doi:10.5065/D6W66HXN.

Zipser, E. J., 1977: Mesoscale and convective-scale downdrafts as distinct components of squall-line structure. Mon. Wea. Rev., 105, 1568-1589, doi:10.1175/1520-0493(1977)105<1568: MACDAD $>2.0 . \mathrm{CO} ; 2$. 